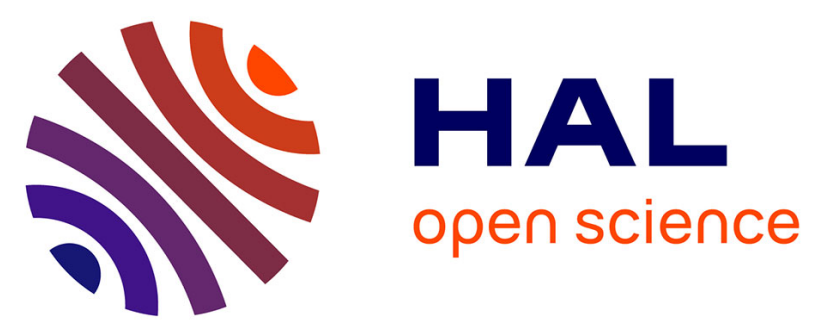

\title{
How intensive agricultural practices and flow regulation are threatening fish spawning habitats and their connectivity in the St. Lawrence River floodplain, Canada
}

Aline Foubert, Frédéric Lecomte, Philippe Brodeur, Céline Le Pichon, Marc Mingelbier

\section{To cite this version:}

Aline Foubert, Frédéric Lecomte, Philippe Brodeur, Céline Le Pichon, Marc Mingelbier. How intensive agricultural practices and flow regulation are threatening fish spawning habitats and their connectivity in the St. Lawrence River floodplain, Canada. Landscape Ecology, 2020, 35 (5), pp.1229-1247. 10.1007/s10980-020-00996-9 . hal-03266237

\section{HAL Id: hal-03266237 https://hal.inrae.fr/hal-03266237}

Submitted on 21 Jun 2021

HAL is a multi-disciplinary open access archive for the deposit and dissemination of scientific research documents, whether they are published or not. The documents may come from teaching and research institutions in France or abroad, or from public or private research centers.
L'archive ouverte pluridisciplinaire HAL, est destinée au dépôt et à la diffusion de documents scientifiques de niveau recherche, publiés ou non, émanant des établissements d'enseignement et de recherche français ou étrangers, des laboratoires publics ou privés. 


\section{Landscape Ecology}

\section{Losing the best conditions for effective fish spawning habitat in the floodplain due to riparian agriculture and flow regulation, St. Lawrence River, Canada. † \\ --Manuscript Draft--}

\begin{tabular}{|c|c|}
\hline \multicolumn{2}{|l|}{ Manuscript Number: } \\
\hline Full Title: & $\begin{array}{l}\text { Losing the best conditions for effective fish spawning habitat in the floodplain due to } \\
\text { riparian agriculture and flow regulation, St. Lawrence River, Canada. } \dagger\end{array}$ \\
\hline Article Type: & Original research \\
\hline Keywords: & $\begin{array}{l}\text { northern pike reproduction; habitat modelling; connectivity modelling; agricultural } \\
\text { landscape; water regulation }\end{array}$ \\
\hline Corresponding Author: & $\begin{array}{l}\text { Céline Le Pichon } \\
\text { Irstea } \\
\text { ANTONY, FRANCE }\end{array}$ \\
\hline \multicolumn{2}{|l|}{$\begin{array}{l}\text { Corresponding Author Secondary } \\
\text { Information: }\end{array}$} \\
\hline Corresponding Author's Institution: & Irstea \\
\hline \multicolumn{2}{|l|}{$\begin{array}{l}\text { Corresponding Author's Secondary } \\
\text { Institution: }\end{array}$} \\
\hline First Author: & Aline Foubert \\
\hline \multicolumn{2}{|l|}{ First Author Secondary Information: } \\
\hline \multirow[t]{5}{*}{ Order of Authors: } & Aline Foubert \\
\hline & Frédéric Lecomte \\
\hline & Philippe Brodeur \\
\hline & Céline Le Pichon \\
\hline & Marc Mingelbier \\
\hline \multicolumn{2}{|c|}{ Order of Authors Secondary Information: } \\
\hline \multicolumn{2}{|l|}{ Funding Information: } \\
\hline Abstract: & $\begin{array}{l}\text { Context } \\
\text { Hydrological and land use changes for human needs, have resulted in the increased } \\
\text { fragmentation of river landscapes and the loss of aquatic habitats, leading to profound } \\
\text { changes in fish diversity and productivity. } \\
\text { Objectives } \\
\text { In the fluvial Lake Saint-Pierre (St. Lawrence River, Canada), we studied how riparian } \\
\text { agriculture and water flow regulation have impacted the effectiveness of spawning } \\
\text { habitats of northern pike (Esox lucius). } \\
\text { Methods } \\
\text { Northern pike spawning and nursery habitats were modelled over a 49-years period } \\
\text { (1965-2013) to estimate effective spawning areas under four contrasted hydrological } \\
\text { conditions. } \\
\text { Results } \\
\text { These simulations, coupled with land-use analyses, revealed that natural flow } \\
\text { conditions usually favourable to fish reproduction have been lost due to human } \\
\text { activities. The highest potential for reproduction, usually associated with high and } \\
\text { stable water flows, has been lost due to (1) intensive agriculture in the upper floodplain }\end{array}$ \\
\hline
\end{tabular}




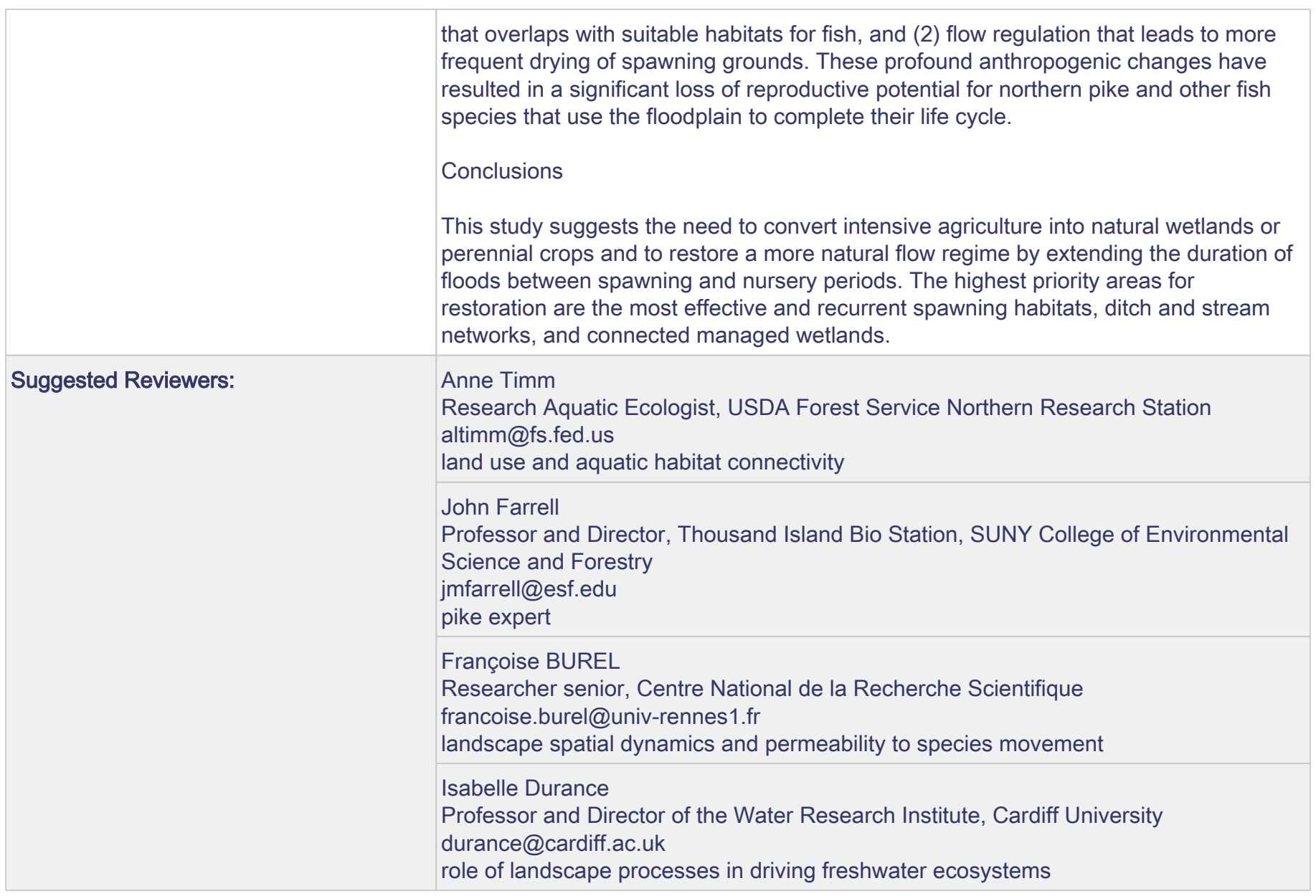


1 Losing the best conditions for effective fish spawning habitat in the floodplain due to

2 riparian agriculture and flow regulation, St. Lawrence River, Canada. $\uparrow$

4 Aline Foubert ${ }^{1,2}$, Frédéric Lecomte ${ }^{1,2}$, Philippe Brodeur ${ }^{3}$, Céline Le Pichon ${ }^{4}$, Marc

$5 \quad$ Mingelbier ${ }^{2}$

6

$7{ }^{1}$ - Université du Québec à Chicoutimi, 555 boulevard de 1'Université, Chicoutimi, G7H

8 2B1, Canada.

$92^{2}$ - Ministère des Forêts, de la Faune et des Parcs, Direction de l'expertise sur la faune

10 aquatique, 880 Chemin Ste-Foy, Québec, QC, G1S 4X4, Canada.

$113^{3}$ - Ministère des Forêts, de la Faune et des Parcs, Direction de la gestion de la faune

12 Mauricie - Centre-du-Québec, 100 rue Laviolette, Trois-Rivières, Qc, G9A 5S9, Canada.

$13^{4}$ - Institut national de Recherche en Sciences et Technologies pour l'Environnement et

14 l'Agriculture, 1 rue Pierre-Gilles de Gennes, CS10030, 92761 Antony cedex, France.

16 Frédéric Lecomte, ORCID iD :0000-0002-8845-1249

17 Celine Le Pichon, ORCID iD: 0000-0001-8055-7164

$18 †$ Contribution to the "Chaire de Recherche sur les Espèces Aquatiques Exploitées"

19 (CREAE)

20

21 Corresponding author: marc.mingelbier@mffp.gouv.qc.ca, 418-627-8694 \# 7484

22 Running title: Losing best spawning conditions due to human activities 


\section{Abstract}

\section{Context.}

26 Hydrological and land use changes for human needs, have resulted in the increased

27 fragmentation of river landscapes and the loss of aquatic habitats, leading to profound

28 changes in fish diversity and productivity.

29 Objectives.

30 In the fluvial Lake Saint-Pierre (St. Lawrence River, Canada), we studied how riparian

31 agriculture and water flow regulation have impacted the effectiveness of spawning habitats

32 of northern pike (Esox lucius).

33 Methods.

34 Northern pike spawning and nursery habitats were modelled over a 49-years period (1965-

35 2013) to estimate effective spawning areas under four contrasted hydrological conditions.

36 Results.

37 These simulations, coupled with land-use analyses, revealed that natural flow conditions

38 usually favourable to fish reproduction have been lost due to human activities. The highest

39 potential for reproduction, usually associated with high and stable water flows, has been

40 lost due to (1) intensive agriculture in the upper floodplain that overlaps with suitable

41 habitats for fish, and (2) flow regulation that leads to more frequent drying of spawning

42 grounds. These profound anthropogenic changes have resulted in a significant loss of

43 reproductive potential for northern pike and other fish species that use the floodplain to

44 complete their life cycle.

45 Conclusions. 
46 This study suggests the need to convert intensive agriculture into natural wetlands or

47 perennial crops and to restore a more natural flow regime by extending the duration of

48 floods between spawning and nursery periods. The highest priority areas for restoration are

49 the most effective and recurrent spawning habitats, ditch and stream networks, and 50 connected managed wetlands.

51

52 Keywords: northern pike reproduction, habitat modelling, connectivity modelling, 53 agricultural landscape, water regulation.

54

55 


\section{Introduction}

57 In unaltered rivers, floodplains are highly productive and dynamical environments at the

58 interface between aquatic and terrestrial ecosystems. They provide a mosaic of temporary

59 habitats required by a wide number of freshwater fish species to accomplish their life cycle.

60 Given the high mortality rate in the early life stages of fishes, quality spawning and nursery

61 habitats are crucial for fish recruitment (Bayler 1991; Gorski et al. 2011). However,

62 floodplains are under increasing anthropogenic pressure around the world (Tockner and

63 Stanford 2002). Impacts of water flow regulation and agricultural expansion are major

64 threats to floodplain ecosystems (Beesley et al. 2014; Fernandes et al. 2015), where

65 potential spawning habitats can turn into mortality traps (e.g. Jeffres and Moyle 2012;

66 Sheaves et al. 2014). Quantifying the effects of anthropogenic pressures on the

67 effectiveness of spawning habitats allows the identification of large-scale environmental

68 disturbances that cause widespread recruitment failures (e.g. Goto et al. 2015), an

69 important prerequisite for restoring and managing floodplain ecosystems.

71 The natural flow regime in floodplains (i.e. magnitude, duration and the periodicity of

72 water levels) is highly variable in space and time, which in turn has a significant driving

73 force on fish habitat surfaces areas and landscape connectivity (Junk et al. 1989; Wiens

74 2002). Although the flooding of large areas for long periods of time can improve the

75 recruitment success of riverine fish, a rapid decrease in water discharge during early

76 development can suddenly dewater or isolate spawning and nursery habitats, resulting in

77 high egg and larvae mortality (Bayler 1991; Gorski et al. 2011). In addition, water flow

78 regulation has significantly altered natural flow regimes in many river systems around the 
79 world, which can be critical for the overall fish production (Nilsson et al. 2005). Reduction

80 in spring water discharges has limited the duration of floods and their inter-annual

81 variability, which has affected the quality of river habitat and resulted in a decline in fish

82 populations (e.g. Farrell et al. 2010; Goto et al. 2015; Mingelbier et al. 2008).

83

84 Land-use change is one of the most important factors altering habitats quality and 85 connectivity on floodplains (Tockner and Stanford 2002). The conversion of large areas of

86 natural floodplains to intensive agricultural practices has resulted in a net loss of fish

87 habitat (Baber et al. 2002), a reduction in the abundance of fish eggs and larvae (Matsuzaki

88 et al. 2011), and threatened the long-term persistence of several fish species (Fernandes et

89 al. 2015). In addition, transportation infrastructure, such as roads along rivers, can

90 disconnect and isolate a significant portion of the floodplain, reducing access to critical

91 habitats (Blanton and Marcus 2014). In contrast, as fish larvae have limited swimming

92 capacities, passive transport at low water current speeds (Schiemer et al. 2003) and

93 landscape features such as ditch networks (Washitani 2007) can facilitate larval dispersal.

94 Such alternative use of man-made structure can help maintain floodplain connectivity in 95 an anthropized landscape.

96

97 In previous work, Foubert et al. (2018) examined spawning and nursery habitats of northern

98 pike (Esox lucius) over the past 50 years to investigate how habitat connectivity and

99 hydrological variability interact to alter the distribution of effective spawning habitat in the

100 St. Lawrence River floodplain, Canada. The northern pike was used as a species model

101 because it is an early-spring spawner, archetypal of the floodplain. Pike recruitment is 
102 positively influenced by the abundance and quality of spawning habitat, high-water

103 temperature and high-water level maintained for several weeks after egg deposition

104 (Casselman and Lewis 1996; Johnson 1957). Pike abundance has recently declined in

105 several major river systems (Boët et al. 1999; Raat 2001), including the St. Lawrence River

106 (Smith et al. 2007). Foubert et al. (2018) defined effective spawning habitats as habitats

107 that permit survival of eggs and larvae, while affording larvae access to nursery areas that

108 are essential for successful recruitment to the adult population. As the simulations were

109 carried out in a reconstructed "unaltered" landscape to measure the intrinsic natural

110 variability of the river, they provided a way to compare a simulated pristine environment

111 with a present-day landscape altered by human activities. In the present study, we

112 hypothesised that effective spawning habitats gradually changed during the 20th century,

113 as water flows were regulated and extensive agricultural practices developed. More

114 specifically, in the Lake Saint-Pierre (St. Lawrence River, Canada), we (1) assess the

115 historical loss of potential pike spawning and nursery habitats by riparian agriculture since

1161965 , (2) test the effects of water flow and land-use changes on connectivity between

117 spawning and nursery habitats under four contrasted hydrological conditions, and (3)

118 estimate the loss of connected habitats due to changes in land-use to identify current

119 effective spawning habitats and the most valuable areas to protect and restore. These three

120 objectives are represented in a conceptual diagram that describes the methodological steps

121 leading to the main results of the study (Fig. 1).

122

123 


\section{$124 \quad$ Method}

\section{Study Area}

126 Lake Saint-Pierre is the largest fluvial lake of the St. Lawrence River (Fig. 2), one of the

127 largest river system in the world, in terms of length $(\sim 1,200 \mathrm{~km})$, watershed area $128\left(1,344,200 \mathrm{~km}^{2}\right)$ and average annual discharge $((10,270 \mathrm{~m} 3 . \mathrm{s}-1$ at Sorel; Morin and

129 Bouchard 2000). Lake Saint-Pierre and its archipelago were included on UNESCO's Word

130 Heritage Biosphere List in 2000. The shallow depth $<3 \mathrm{~m}$, slow lateral slope of the bottom,

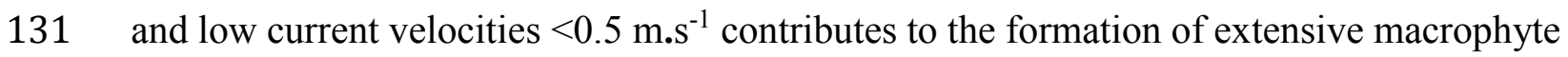

132 beds (Centre-Saint-Laurent 1998). The annual variability of spring water discharges,

133 ranging between 6,500 and $17,500 \mathrm{~m}^{3} \cdot \mathrm{s}^{-1}$ at Sorel, is a key mechanism for maintaining

134 wetland vegetation in floodplains (Morin et al. 2005).

136 Since the beginning of the industrial era, cumulative anthropogenic pressures have altered

137 the Lake Saint-Pierre ecosystem. The gradual excavation of the navigation channel (now

$13811.3 \mathrm{~m}$ deep and $\sim 250 \mathrm{~m}$ wide) between Montreal and Quebec City began around 1840 and

139 was completed in 1998. Water regulation in the St. Lawrence River began in 1911 with the

140 harnessing of the Ottawa River, its main tributary, for hydroelectric power generation,

141 flood control and navigation purposes. The regulation of the St. Lawrence River was

142 further enhanced by the construction of the Moses-Saunders and Beauharnois Power Dams

143 that control the Lake Ontario - St. Lawrence River system in 1958 (Carpentier 2003; Morin

144 and Bouchard 2000). In addition, the development of large urban centres (e.g. Montreal,

145 Trois-Rivières, and Quebec City), intensive agriculture along the river and in the

146 floodplain, and transportation infrastructures along the St. Lawrence River have had a 
147 serious impact on fish habitat. Over time, perennial crops (e.g. pasture), which constitute

148 potential fish habitat in the floodplain, have been replaced by annual crops (e.g. corn, soya)

149 with no potential for fish spawning; this phenomenon has accelerated since the early 1990s

150 (de la Chenelière et al. 2014; Fecteau and Poissant 2001). To compensate for the loss of

151 fish habitat, approximately 1,300 ha of the Lake Saint-Pierre floodplain have been

152 managed since the 1980s (Mingelbier and Douguet 1999). Managed wetlands are

153 surrounded by dikes and partially controlled to maintain high and stable water levels,

154 extend the duration of spring floods and accelerate water warming. During spring floods,

155 fish use these managed wetlands to spawn and are then evacuated in early June to Lake

156 Saint-Pierre.

157

158 Data collection

159 Potential habitat modelling in an unaltered floodplain (1965-2013)

160 Several high spatial resolution hydrodynamic and biological models have been developed

161 in the St. Lawrence River by Environment Canada to simulate the vegetation of the

162 floodplain (e.g. deep marshes, shallow marshes and shrub) in Lake Saint-Pierre under

163 various hydrological conditions (Morin et al. 2000; Morin et al. 2003; Turgeon and Morin

164 2005). Thus, natural plant succession in the littoral zone could be rebuilt each year for the

165 period 1965 to 2013. As these simulations exclude anthropogenic effects, we used them to

166 estimate the full reproductive habitat potential of northern pike in a natural environment

167 for each year of the 1965-2013 period. Habitat quality indices (HSIs) were developed to

168 map the maximum spawning habitat (Week 0 : the date varies every year according to water

169 temperature, developed in Mingelbier et al. 2008) and nursery habitat five weeks after the 
170 start of the free-swimming stage (HSI nursery at Week, developed and described in Foubert

171 et al. 2018).

172

173 Land-use categories

174 Land-use in the Lake Saint-Pierre floodplain was described for three reference years: using

175 aerial photographs in 1964 and 1997 (Richard et al. 2011) and satellite images in 2014

176 (Jobin and Dauphin in prep). In the present study, we interpreted the various types of land-

177 use and assigned six land-use categories, from most suitable to least suitable for pike

178 reproduction habitats: (1) wetlands suitable for spawning and nursery habitats (e.g. wet

179 meadow and marshes), (2) main ditch and stream networks, (3) perennial crops (e.g.

180 pasture and forage crops), (4) unsuitable wetlands and wooded areas (e.g. wooded peat

181 bogs and plantations), (5) roads and urban areas, and finally (6) annual crops (i.e. soya,

182 corn, wheat, vegetable crops, oat, barley and other cereals) (see all land-use types and their

183 associated habitat quality in Online Resource 1). Only treed swamps differed in quality

184 between spawning and nursery habitats. We considered treed swamps being suitable for

185 nurseries (e.g. food supply) but unsuitable for spawning due to the lack of appropriate

186 substrate for egg deposition. In addition, the managed wetlands were included in the

187 analysis because they are used by pike and other fish species during their early stages of

188 development (Mingelbier and Douguet 1999 updated with field observations: see Fig.1).

189 The next three sections explain the analyses performed, which are illustrated in the 190 conceptual diagram Fig. 1.

192 Historical habitat losses by agriculture (objective 1) 
193 As annual crops gradually increased between 1964, 1997 and 2014, we conducted a linear

194 interpolation using these three reference years to estimate annual habitat area losses

195 between 1965 and 2013. The loss of spawning and nursery related to annual crops was

196 calculated for each year by superimposing the corresponding land-uses and habitats.

197 Spearman's Rank correlation coefficients were used to assess (1) the relationship between

198 total potential spawning habitat lost due to annual crops and water discharge at spawning

199 (Week $)_{0}$ and (2) the relationship between total potential nursery habitat lost due to annual

200 crops and water discharge when larvae became free-swimming (Weeks).

201

202 Habitat connectivity for four hydrological profiles (objective 2)

203 Selected hydrological profiles

204 Since the flow regime largely varied over the study period (1965-2013), the water

205 discharge between the maximum spawning time $\left(W_{e} \mathrm{k}_{0}\right)$ and the free-swimming stage

206 (Weeks) was classified into four distinct profiles: (1) stable-low, (2) stable-high, (3)

207 increasing and (4) decreasing. Four years of the 1965-2013 period were chosen to represent

208 the four profiles to assess their influence on pike spring spawning dynamics $(1965,1973$,

2091983 and 1998, respectively; Tab.1). Historical analysis covering the 1965-2013 period

210 revealed that the profile recurrences were $16 \%$ for stable-low, $16 \%$ for stable-high, $14 \%$

211 for increasing and 53\% for decreasing discharges. Profile recurrences were also calculated

212 for the natural flow regime reconstructed by Morin and Bouchard (2000) for the period

213 1883-1910 preceding the Ottawa River regulation. During this unregulated period, all

214 profiles were increasing (61\%), or stable (39\%) between Week 0 and Week 5 (Le Pichon et

215 al. 2018). 


\section{Connectivity estimate}

218 A least-cost approach to modelling movement in landscapes (Adriaensen et al. 2003) was

219 used to quantify connectivity between spawning habitat at Week 0 and nursery habitat at

$220 W^{2} k_{5}$. In this model, every landscape element is assigned a 'resistance' value based on its

221 restricting/facilitating effects on animal movements (i.e. Minimal Cumulative Resistance

222 concept) in both upstream and downstream directions (e.g. Caldwell and Gergel 2013;

223 Hanke et al. 2013; Roy and Le Pichon 2017). Foubert et al. (2018) described in detail the

224 method used to measure connectivity between two types of habitats (e.g. flowchart and

225 functional distance examples).

227 We assigned a resistance value to hydrological and land-use characteristics that simulate

228 different risks of larval mortality (e.g. fast current, dewatering, dense vegetation) or larval

229 dispersion (i.e. passive drift and active swimming) when they leave spawning habitats.

230 First, the environmental characteristics of the landscape sensitive to hydrological variations

231 were considered. The resistance values were adapted from Foubert et al. (2018) and

232 allowed the combined effects of water discharge and current velocities on egg survival and

233 larval dispersal to be assigned to each point (or pixel) of the modelled landscape (see

234 Tab.2). A maximum resistance value preventing any survival or successful dispersal was

235 assigned to dewatered areas (water depth $\leq 0 \mathrm{~cm}$ ) and current velocities $>10 \mathrm{~cm} \cdot \mathrm{s}^{-1}$ (Peake

236 2004). Resistance values $<1$, reflecting current-assisted larval drift, were assigned to

237 current velocities ranging from 2 to $10 \mathrm{~cm} \cdot \mathrm{s}^{-1}$. A maximum resistance value has been

238 assigned to dense vegetation (e.g. wet meadows and shrubby swamps in low water depths 
$239<20 \mathrm{~cm}$ ), since they can act as physical barriers to larval dispersal (see Tab.2). Second,

240 anthropogenic features that restrict (i.e. emerged roads and managed wetland dikes) or

241 facilitate (i.e. ditch and stream networks) dispersion in the contemporary landscape were

242 also examined. We have differentiated submerged roads and managed wetland dikes that

243 influence connectivity. The accuracy of the topographic measurements (every meter)

244 provided by LiDAR and the simulated water depths allowed us to identify submerged and

245 emerged elements for contrasting hydrological conditions in the lake. A maximum

246 resistance value has been assigned to emerged roads and managed wetland dikes (e.g.

247 larvae cannot cross them). In addition, permanent structures (i.e. culverts, water control

248 structures and weirs) allowing larvae to cross roads and managed wetlands dikes have been

249 identified from published material (Mingelbier and Douguet 1999), field observations and

250 GIS analyses. When a road has been cut by a ditch or a stream, a culvert has been

251 considered. A resistance value of 1 that does not involve any restriction or facilitation of

252 movement (i.e. only larval swimming capacity is considered) was assigned to permanent

253 structures, ditches and stream networks (see Tab.2). The types of agricultural crops in the

254 contemporary landscape were not included in connectivity estimates as they are not

255 believed to completely restrict connectivity or cause mortality during larval movement.

257 After assigning resistance values, we used the open source software Anaqualand 2.0 (Le

258 Pichon et al. 2006) to generate the functional distance between spawning and nursery

259 habitats (Foubert et al. 2018). The functional distance is defined as the combination of

260 larvae dispersal potential (i.e. mobility coefficient ( $\alpha)$ defined below) and the sum of the

261 resistance the larvae will encounter along their path. The mobility coefficient $(\alpha)$ is 
262 derived from the stage-specific larval swimming capacities and the potential passive

263 transport provided by local currents at the beginning of the free-swimming stage (Week 5 ).

264 The maximal value was set to $\alpha=6000 \mathrm{~m}$ which corresponds to the maximal distance

265 travelled at $1 \mathrm{~cm} \cdot \mathrm{s}^{-1}$ by a neutral particle in the water column over a one-week period in the

266 St. Lawrence River (see sensitivity analyses in Online Resource 2). Since the functional

267 distance incorporates resistance values, it does not always correspond to a physical

268 instream distance (i.e. minimum distance within the limits of the watercourse).

270 Connected and disconnected spawning habitats

271 When the functional distance between a spawning habitat and a nursery was

$272 \leq 6000 \mathrm{~m}$ functional (i.e. the maximal mobility coefficient), the spawning habitat was

273 considered to be connected (Foubert et al. 2018). However, when the functional distance

274 exceeded $6000 \mathrm{~m}$ functional, the spawning habitat was considered disconnected. Connected

275 and disconnected spawning habitats were mapped in $\operatorname{ArcGIS} 10.1$ and their surfaces were

276 quantified (surface expressed in ha) for the four selected hydrological profiles (1965. 1973,

2771983 and 1998).

278

279 In addition, the effects of each hydrological and land-use characteristic added successively 280 on connectivity estimate (i.e. water depth, current speed, dense vegetation and 281 roads/managed wetland dikes) were quantified (Tab.3). Direct losses correspond to 282 potential spawning habitats spatially superimposed on restricted landscape features.

283 Technically, spawning habitats were superimposed on landscape features in ArcGIS 10.1

284 to estimate (1) spawning habitats lost due to dewatering occurring between Week 0 and 
285 Week $_{5}$ (water depth $\leq 0$, Tab.2), (2) spawning habitats lost due to increased current

286 velocities $\left(>10 \mathrm{~cm} \cdot \mathrm{s}^{-1}\right),(3)$ emerged roads, and (4) dense vegetation. Indirect losses are

287 potential spawning habitats that are not connected to a nursery because of limited landscape

288 features that act as physical barriers to larvae dispersal.

290 Effective spawning habitats (objective 3)

291 For the four selected hydrological profiles, the total area of connected spawning habitats

292 (i.e. including the effects of water depth, current velocity, dense vegetation, ditch and

293 stream networks, and emerged roads/managed wetland dikes) was superimposed on the six

294 land-use categories of the contemporary description (i.e. 2014) in ArcGIS 10.1. It allowed

295 us to quantify and differentiate the area of (1) effective spawning habitat, which

296 corresponds to the overlap of connected spawning habitats with suitable land-use

297 categories (i.e. suitable wetlands, perennial crops and drainage ditches), and (2) ineffective

298 spawning habitat that overlaps with inadequate land-use categories (i.e. unsuitable

299 wetlands and wooded, annual crops, and roads and urban areas). Finally, the effective

300 spawning habitat areas obtained for the four hydrological profiles (i.e. stable-low, stable-

301 high, increasing and decreasing water discharges) were spatially overlaid to identify the 302 most recurrent effective spawning habitats. 


\section{$305 \underline{\text { Results }}$}

\section{Historical habitat losses related to agriculture}

307 With the expansion of intensive agricultural practices, up to 2,446 ha of potential spawning

308 habitats and 1,188 ha of potential nursery habitats have been lost in the Lake Saint-Pierre

309 floodplain between 1965 and 2014 (see Fig. 3). The impacts of agriculture have been

310 particularly severe since 1990 , resulting in a total area of spawning habitats of no more

311 than 5,500 ha. The total loss of both spawning and nursery habitats was positively

312 correlated with water discharges at Week 0 and at Weeks, respectively $(P<0.05$, Spearman's

313 rank correlation). The impact of agriculture on potential spawning and nursery habitats

314 occurred at discharges $>12,000 \mathrm{~m}^{3} \cdot \mathrm{s}^{-1}$ with the largest losses at discharges $>14,000 \mathrm{~m}^{3} \cdot \mathrm{s}^{-1}$

315 (Fig 2).

316

317 Habitat availability and connectivity

318 Potential habitats during contrasting hydrological profiles

319 The total area of potential spawning and nursery habitats available annually was

320 determined by hydrological conditions (Tab.1, Fig. 4). High spring water discharges

321 resulted in a large area of potential spawning (1998) and nursery habitats (1983), while low

322 water discharges resulted in the smallest areas of potential spawning habitats (1965) and

323 decreasing profile led to the smallest areas of potential nursery habitats (1998). At medium

324 to high water discharges, managed wetlands generated up to 571 ha and 722 ha of potential

325 spawning and nursery habitats respectively, which represent between $10 \%$ and $13 \%$ of the

326 maximum habitat available in the Lake Saint-Pierre 
329 Due to hydrological variability and anthropogenic landscape characteristics on habitat 330 connectivity, eight to $68 \%$ of potential spawning habitats were lost (dewatering or

331 disconnected nurseries; Tab.3). Firstly, the largest disconnected spawning areas appeared 332 during the decreasing profile between the maximum spawning time $\left(W_{e} \mathrm{k}_{0}\right)$ and the free333 swimming stage $\left(\mathrm{Week}_{5}\right.$ ) due to the dewatering of $62 \%$ of potential spawning areas.

334 Secondly, the increase in water currents above the $10 \mathrm{~cm} \cdot \mathrm{s}^{-1}$ thresholds after spawning has

335 transformed high-quality habitats into low-quality habitats. These conditions appeared

336 frequently during the increasing profile. These fast water currents acting as physical

337 barriers prevented access to $2 \%$ of spawning habitats during the increasing profile. Thirdly,

338 the dense vegetation slightly reduced the total surface of potential spawning habitats (1\%)

339 during the stable-high and decreasing profiles and acted as a physical barrier during the

340 decreasing profile. Fourthly, $2 \%$ of potential spawning habitats have disappeared in stable-

341 high and decreasing profiles due to the surface occupied by the emerged roads. Although

342 spawning habitat losses were small, emerged roads also served as physical barriers during

343 stable-high profiles.

344

345 The largest area of connected spawning habitat occurred during the stable-high profile, 346 one-third resulting from the overlap between potential spawning and nursery habitats, and

347 two-thirds related to the larval mobility coefficient ( $\alpha=6000 \mathrm{~m}$ functional), connecting

348 potential spawning areas to distant nursery areas (Fig. 5). The overlap between potential

349 spawning and nursery habitats generate large areas of connected spawning habitats, 350 especially when water discharge remains stable between Week 0 and Week 5 . The 
351 overlapping habitat areas reached $55 \%$ of the total connected spawning area in the stable-

352 low profile, $28 \%$ in the stable-high profile, $0.2 \%$ in the increasing profile and $10 \%$ in the

353 decreasing profile (see dark blue in Fig. 5). Moreover, larval mobility ( $\alpha$ ) allowed to reach

354 distant nursery habitats when (1) few potential spawning and nursery habitats overlapped,

355 and (2) hydrological conditions maintained large spawning areas during the five first weeks

356 of ontogeny and created large nursery area (Fig. 5). The total area of connected spawning

357 habitat increased by $61 \%$ in the stable-high profile and by $81 \%$ in the increasing profile

358 due to larval mobility ( $\alpha$ ). When fewer spawning habitat areas are available at the

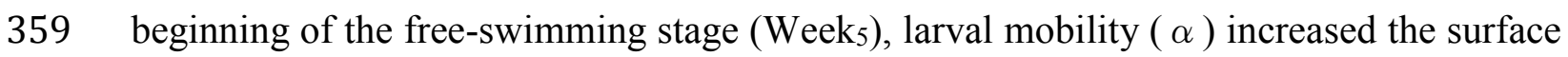

360 of connected spawning habitat by $36 \%$ (stable-low profile) and by $21 \%$ (decreasing

361 profile). During the decreasing profile, ditch and stream networks in dewatered areas

362 further increased the surface of connected spawning habitats by $14 \%$ ( 252 ha) (Online

363 Resource 2). Finally, managed wetlands generated 463 ha (10\%) of total connected

364 spawning habitat areas during the stable-high profile, 439 ha (12\%) during the increasing

365 profile and 216 ha (11\%) during the decreasing profile.

\section{Effective spawning habitats}

368 Considering the latest Lake Saint-Pierre floodplain described (e.g. satellite images taken in

369 2014; Jobin and Dauphin in prep), from zero to $47 \%$ of the connected spawning habitats

370 were not effective due to unsuitable land-use categories (Fig. 6). The largest loss of

371 connected spawning habitat was observed for the stable-high profile with $32 \%$ of non-

372 effective surfaces related to agricultural practices, mostly used for corn and soybean

373 production. When water discharges reached average $\left(\sim 11,000 \mathrm{~m}^{3} \cdot \mathrm{s}^{-1}\right)$ to high 
$374\left(\sim 15,000 \mathrm{~m}^{3} . \mathrm{s}^{-1}\right)$ discharges during the first five weeks of ontogeny (i.e. in 1973, 1983 and

375 1998), unsuitable wetlands and wooded areas reduced the surface of connected spawning

376 areas by $11 \%$ to $14 \%$. Less than $1 \%$ of connected spawning area was lost due to the

377 presence of submerged roads and urban areas in the four hydrologic profiles. Finally, only

$3780.4 \%$ of connected spawning area was affected by land-use during the stable-low profile.

380 Considering contemporary land-use changes in connected spawning habitats, the increase

381 in water discharge between the maximum spawning time (Week $)$ and the free-swimming

382 stage (Weeks), which ranges from medium to high, was found to be the most favourable

383 hydrological conditions for northern pike habitats in Lake Saint-Pierre (increasing profile

384 in Fig. 7). In this case, 3,218 ha, corresponding to $70 \%$ of the initial potential spawning 385 area, were connected to nursery areas and were not modified by unsuitable land-use

386 (= effective spawning habitats). During the stable-low profile, almost all the potential

387 spawning areas were effective for northern pike recruitment (i.e. 2,549 ha or $91 \%$ of

388 potential habitats). During the stable-high profile, similar potential spawning areas

389 remained effective (i.e. 2,463 ha), but represent only $47 \%$ of the potential spawning area.

390 This significant decrease is due to agricultural practices. During the decreasing profile,

391 potential habitats altered by the land-use have already been lost due to hydrological

392 constrains on habitat connectivity. Although only $27 \%$ (1,628 ha) of the potential spawning

393 habitats remained effective, only 15\% (279 ha) of connected spawning habitats were

394 altered by the land-use. Finally, 332 ha of effective spawning habitats were spatially

395 recurrent over the four contrasting hydrological profiles (dark green in Fig. 7). 
398 This study shows that anthropogenic alterations to the floodplain and hydrological regime

399 have major effects on the availability and the connectivity of habitats for early life history

400 stages of fishes. The various habitat and connectivity models, carried out under highly

401 contrasting hydrological conditions over the past 50 years, and combined with a description

402 of land use for several reference periods, have proven to be very effective in identifying

403 the regions of the Lake Saint-Pierre most impacted by human alterations. To measure the

404 effects of human pressures, it was first necessary to produce reference conditions

405 representing an unaltered landscape and to assess the intrinsic natural variability of the

406 river, which was accomplished by Foubert et al. (2018). In the present study, the modelling

407 was carried out in a present-day landscape altered by two main human landscape pressures.

408 Results revealed that water flow regulation in the river system and increasing agriculture

409 in the floodplain significantly reduced the spawning habitats effectiveness of species such

410 as northern pike that use the upper littoral zone of a river. Together, these two pressures

411 dramatically reduced the range of natural conditions favourable to fish reproduction in the

412 St. Lawrence River. The highest natural reproductive potential for northern pike, usually

413 associated with high and stable water flows (Casselman and Lewis 1996; Johnson 1957),

414 has been lost due to (1) intensive agricultural practices in the upper floodplain that overlaps

415 with suitable natural habitats for fish, and (2) flow regulation that leads to more frequent

416 drying of spawning grounds and egg mortality. These profound anthropogenic changes in

417 the St. Lawrence River have resulted in a significant loss of reproductive potential for

418 northern pike and other fish species that use the floodplain to complete their life cycle. 
419 In a context of global climate change, where spring water discharge is expected to decrease

420 and extreme hydrological conditions to increase in frequency (Boyer et al. 2010; Mortsch

421 et al. 2000), effective spawning habitats in Lake Saint-Pierre could be further reduced,

422 which could make it impossible to maintain fish abundance at their past levels. Hence,

423 restoring habitat quality and connectivity in floodplains coupled with better flow regime

424 management will play an important role in conserving biodiversity and maintaining

425 sustainable populations.

\section{Land-use changes and potential habitat loss}

428 Changes in land-use have profoundly altered potential fish habitats in productive

429 floodplains (e.g. Baber et al. 2002; Blanton and Marcus 2014; Fernandes et al. 2015). The

430 Lake Saint-Pierre floodplain has been progressively occupied by agriculture. While in 1950

431 perennial crops dominated $(\approx 45 \%$ cover, $\approx 21,000-22,000$ ha) and annual crops accounted

432 for only 10 to $15 \%$ of the territory $(\approx 5,000$ to $7,000 \mathrm{ha})$, the situation completely reversed

433 in the 1990s since annual crops dominated, occupying 32\% of the Lake Saint-Pierre

434 (16,000 ha) compared to $15 \%$ (7,000 ha) for perennial crops. Although perennial crops (i.e.

435 pasture and forage crops) can represent potential fish habitat, ploughing annual crops

436 remove vegetation cover and create bare fields without substrate for egg laying in the next

437 spring. The present study has shown that annual crops have negative effects on northern

438 pike habitats especially when the water flow in Sorel exceeds $14,000 \mathrm{~m}^{3} \cdot \mathrm{s}^{-1}$, which happens

439 very often in the spring (annually or biannually; Morin and Bouchard 2000). Indeed, large

440 potential habitat losses were observed during high water discharges because fish habitats 
441 overlapped with unsuitable land-use due to agricultural practices that are mainly located in

442 the upper part of the floodplain.

\section{Habitat connectivity}

445 In large floodplains, not all potential spawning habitats are connected to a nursery area,

446 and therefore become mortality traps (Jeffres and Moyle 2012; Sheaves et al. 2014).

447 Although transportation infrastructures (i.e. roads) have had impacts on habitat

448 connectivity in the Lake Saint-Pierre floodplain (Le Pichon et al. 2018), rapid dewatering

449 during the five first weeks of ontogeny appears to be the main factor limiting connectivity

450 between northern pike spawning and nursery habitats (Foubert et al. 2018). Rapid

451 dewatering after pike eggs were laid revealed large areas of spawning habitat in mortality

452 traps (3 758 ha or $62 \%$ of potential habitats). In addition, a decreasing profile can transform

453 moderately dense vegetation associated with high quality spawning and nursery habitats

454 (Casselman and Lewis 1996; Timm and Pierce 2015) into very dense low oxygen

455 macrophyte beds (Casselman 1978; Holland and Huston 1984). Although only increasing

456 (61\% of all years) or stable (39\%) hydrological profiles were observed before water flow

457 regulation (1883-1910) (Le Pichon et al. 2018), the most recurrent condition since 1965

458 has been a steadily decreasing profile between the spawning time ( $\left.\mathrm{Week}_{0}\right)$ and the larvae

459 free-swimming period (Week ${ }_{5}$ ). The regulation of the Ottawa River, considered the main

460 tributary of the St. Lawrence River with a water discharge ranging from 570 to $9,200 \mathrm{~m}^{3} \cdot \mathrm{s}^{-1}$

461 (Carpentier 2003), has now increased hydrological conditions generating large

462 disconnected spawning areas in Lake Saint-Pierre (e.g. Brodeur et al. 2006). With the

463 regulation of the Ottawa River, the duration of the flood has been shortened by three weeks 
464 and the maximum annual water discharge has decreased significantly by nearly

$4652,500 \mathrm{~m}^{3} \cdot \mathrm{s}^{-1}$, a decrease exacerbated by the regulation of Lake Ontario outflows since 1958

466 (i.e. reduction of $1,020 \mathrm{~m}^{3} \cdot \mathrm{s}^{-1}$; Morin and Bouchard 2000).

467

468 In large floodplains characterized by recurrent dewatering profiles where intensive

469 agricultural practices are covering large expanse of the landscape, managed wetlands and

$470 \mathrm{ditch} /$ stream networks appear to be key landscape features facilitating habitat connectivity

471 due to their permanent aquatic characteristic (e.g. Washitani 2007). Our results highlighted

472 the role of these two anthropogenic landscape features in maintaining connected spawning

473 habitats in the upper part of the Lake Saint-Pierre floodplain, where potentially flooded

474 areas have become vulnerable to dewatering and agricultural expansion (e.g. in 1998 and

4751973 in Saint-Barthélemy Bay). Although managed wetlands are accessible only at

476 medium to high water discharges (Brodeur et al. 2004), they promote spatial overlap of

477 spawning and nursery habitats that improve larval growth and survival (Ospina-Alvarez et

478 al. 2012; Schiemer et al. 2001). In addition, when spawning and nursery habitats are

479 spatially separated, ditch and stream networks can be used by mobile individuals to connect

480 nursery habitats (e.g. Ishiyama et al. 2014). Although young pike larvae have limited

481 swimming capacities, low current speeds in large floodplains favour dispersal of larvae to

482 nurseries (Miehls and Dettmers 2011; Schiemer et al. 2003). Several independent

483 observations in Lake Saint-Pierre confirmed the presence of northern pike larvae in ditch

484 and stream networks and managed wetlands considered effective spawning and nursery

485 habitats in this study (Brodeur et al. 2016). 


\section{Effective spawning habitats}

488 Natural hydrological conditions, that are favourable for fluvial fish recruitment in large

489 unaltered floodplains because they generate large areas of effective habitats (Gorski et al.

490 2011; Junk et al. 1989), have lost their benefits due to anthropogenic pressures. Although

491 a stable-high hydrological profile $\left(>14,000 \mathrm{~m}^{3} \cdot \mathrm{s}^{-1}\right)$ in Lake Saint-Pierre generated large

492 areas of potential spawning habitats connected to nurseries (4,665 ha), only $47 \%$ were

493 effective when land-use was considered. The expansion of intensive agriculture,

494 particularly annual crops, has profoundly altered spawning habitats that were previously

495 connected to nurseries. Historically, 1,517 ha of these habitats were effective for northern

496 pike during favourable hydrological conditions (i.e. stable-high profile represented by

497 1973). In addition, water flow regulation has dramatically reduced the frequency of these

498 favourable hydrological conditions (see above) (Le Pichon et al. 2018), which have

499 naturally generated large interconnected habitats. As a result, the possibility for stable-high

500 hydrological profiles could produce high potentials for northern pike reproduction was rare

501 and systematically eliminated by intensive agricultural practices, especially since 1990

502 (Martin and Létourneau 2011).

503

504 Under specific hydrological conditions, anthropized floodplains can still generate large

505 effective spawning habitats. In Lake Saint-Pierre, 3,218 ha of effective spawning habitats

506 were estimated during the increasing profile - i.e. when the water discharge increased from

507 medium to high between the maximum spawning time $\left(W_{e} \mathrm{k}_{0}\right)$ and the free-swimming

508 stage (Weeks). Potential spawning habitats generated by medium water discharge were (1)

509 not disconnected by hydrological variability during the increasing profile and (2) not 
510 altered by land-use activities in the upper floodplain. In addition, years of low water

511 discharges are the less affected by intensive agriculture since they maintain their full habitat

512 potential, although low. Nevertheless, the increasing profile and the stable profile, which

513 produce the largest effective spawning habitat areas in the anthropised floodplain of Lake

514 Saint-Pierre, has been greatly reduced by the regulation of water flow (Le Pichon et al.

515 2018).

516

517 Management implications

518 In conclusion, the loss of conditions favouring the formation of vast potential spawning

519 habitats for northern pike caused by intensive agricultural practices in the floodplain and

520 flow regulation represents a serious constraint, as several fish populations show a

521 significant decline in the St. Lawrence River. This study highlights important new

522 opportunities to improve fish habitat and recruitment in major river systems such as the St.

523 Lawrence River, and identifies the following priority management measures.

524

525 First, to regain production potential in years with high water flows, the priority would be

526 to convert large intensive annual crops located in the floodplain to natural wetlands, or at

527 least to perennial crops that represent potential fish habitat. Such actions are much needed

528 for improving the health of the St. Lawrence River ecosystem (e.g. Gagliardi and

529 Pettigrove 2013; Washitani 2007). Field crop conversions should target areas where large

530 connected habitats are altered by annual crops such as the Saint-Barthélemy Bay (Fig. 2,

531 Fig. 7).

532 
533 Second, existing structures such as ditches and stream networks should be maintained as

534 they represent effective fish habitats and contribute to habitat connectivity (Beier and Noss

535 1998). In some particular cases, additional structures could be installed if required by local

536 needs. Although transportation infrastructures (roads) can limit connectivity in floodplains

537 (Blanton and Marcus 2014; Doyle et al. 2008), structures such as culverts have proven to

538 be useful in maintaining connectivity in anthropized floodplains (Douven et al. 2012; Le

539 Pichon et al. 2018).

540

541 Third, managed wetland developed in the Lake Saint-Pierre floodplain show great potential

542 for increasing the survival of early-life history stages of fishes. Indeed, these managed

543 marshes are surrounded by dikes that could extend the duration of the flood, as was the

544 case during the non-regularized period of the St. Lawrence system, while maintaining

545 connectivity between spawning and nursery habitats, which is also positive for the survival

546 of young fish.

547

548 Fourth, the water discharge regulation of the Ottawa River since 1911 has altered the

549 natural flow regime of the St. Lawrence River, decreasing the average water level of spring

550 floods in Lake Saint-Pierre by $\sim 0.75 \mathrm{~m}$ and reducing its duration by about 3 weeks (Morin

551 and Bouchard 2000). Our simulations suggest that a revision of flow management rules in

552 the Ottawa River to restore a more natural spring flow regime could benefit species that

553 use the floodplains of the St. Lawrence River, for example by extending the duration of

554 spring floods to ensure better connectivity between spawning and nursery habitats. This

555 type of rules revision was conducted in the Lake Ontario-St. Lawrence River basin by the 
556 International Joint Commission (IJC), established under the 1909 Boundary Waters Treaty

557 Act between the United States and Canada, which approved a new management plan in 5582016 that allowed for more natural water level variations. In comparison, the changes

559 induced by the regulation of the Ottawa River are much less known and receive little 560 consideration.

561

562 


\section{Acknowledgments}

564 This study would not have been possible without the contribution of the members of the

565 Thousand Islands Biological Station for conducting field experiences and Sylvain Martin

566 for exporting hydrological data. A special thank goes to Dr. Mathieu Cusson for revisions

567 of earlier version of the manuscript. This study is part of A.F.'s Ph.D. thesis. Financial

568 support was provided by grants from the "Chaire de Recherche sur les Espèces Aquatiques

569 Exploitées", the Ministère de la Faune, des Forêts et des Parcs du Québec (MFFP), the

570 "Ressources Aquatiques Québec", and the "Commission permanente de coopération

571 franco-québécoise".

572

573 


\section{References}

575 Adriaensen F, Chardon JP, De Blust G et al (2003) The application of 'least-cost'

576 modelling as a functional landscape model. Landscape and Urban Planning 64(4):233-247

577 Baber MJ, Childers DL, Babbitt KJ, Anderson DH (2002) Controls on fish distribution and

578 abundance in temporary wetlands. Canadian Journal of Fisheries and Aquatic Sciences

579 59(9):1441-1450

580 Bayler PB (1991) The flood pulse advantage and the restoration of river-floodplain

581 systems. Regulated rivers: Research \& Management 6:75-86

582 Beesley L, King AJ, Gawne B et al (2014) Optimising environmental watering of

583 floodplain wetlands for fish. Freshwater Biology 59:2024-2037

584 Beier P, Noss R (1998) Do Habitat Corridors Provide Connectivity? Conservation Biology

585 12:1241-1252

586 Blanton P, Marcus WA (2014) Roads, Railroads, and Floodplain Fragmentation Due to

587 Transportation Infrastructure Along Rivers. Annals of the Association of American 588 Geographers 104:413-431

589 Boët P, Belliard J, Berrebi-dit-Thomas R, Tales E (1999) Multiple human impacts by the

590 City of Paris on fish communities in the Seine river basin, France. Hydrobiologia 410:59-

59168

592 Boyer C, Chaumont D, Chartier I, Roy AG (2010) Impact of climate change on the

593 hydrology of St. Lawrence tributaries. Journal of Hydrology 384(1-2):65-83

594 Brodeur P, Mingelbier M, Morin J (2004) Impacts des variations hydrologiques sur les

595 poissons des marais aménagés du Saint-Laurent fluvial. Le Naturaliste Canadien

596 128(2):66-77

597 Brodeur P, Mingelbier M, Morin J (2006) Impact de la régularisation du débit des Grands

598 Lacs sur l'habitat de reproduction des poissons dans la plaine inondable du fleuve Saint-

599 Laurent. Le Naturaliste Canadien 130:60-68

600 Brodeur P, Simard A, Théberge M, Bacon R (2016) Suivi du segment 8 du complexe 601 d'aménagement de Baie-du-Febvre / Nicolet Sud. Bilan des activités 2009-2014. Ministère 602 des Forêts, de la Faune et des Parcs. Direction de la gestion de la faune de la Mauricie et 603 du Centre-du-Québec, pp. 69 
604 Caldwell IR, Gergel SE (2013) Thresholds in seascape connectivity: influence of mobility, 605 habitat distribution, and current strength on fish movement. Landscape Ecology 606 28(10):1937-1948

607 Carpentier A (2003) La régularisation du Saint-Laurent. Le Naturaliste Canadien 127:102$608 \quad 113$

609 Casselman JM (1978) Effects of environmental factors on growth, survival, activity, and 610 exploitation of northern pike. American Fisheries Society Spec. Publ. 11:114-128

611 Casselman JM, Lewis CA (1996) Habitat requirements of northern pike (Esox lucius). 612 Canadian Journal of Fisheries and Aquatic Sciences 53:161-174

613 Centre-Saint-Laurent (1998) Le fleuve en bref: capsules-éclair sur l'état du Saint-Laurent.

614 Environnement Canada, Région du Québec: Saint-Laurent Vision 2000, pp. 121

615 de la Chenelière V, Brodeur P, Mingelbier M (2014) Restauration des habitats du lac Saint616 Pierre: un prérequis au rétablissement de la perchaude. Le Naturaliste Canadien 138:50-61

617 Douven W, Buurman J, Beevers L et al (2012) Resistance versus resilience approaches in 618 road planning and design in delta areas: Mekong floodplains in Cambodia and Vietnam. 619 Journal of Environmental Planning and Management 55:1289-1310

620 Doyle MW, Stanley EH, Havlick DG et al (2008) Aging Infrastructure and Ecosystem 621 Restoration. Science 319:286-287

622 Farrell JM, Murry BA, Leopold DJ et al (2010) Water-level regulation and coastal wetland 623 vegetation in the upper St. Lawrence River: inferences from historical aerial imagery, seed 624 banks, and Typha dynamics. Hydrobiologia 647:127-144

625 Fecteau M, Poissant L (2001) Survol des impacts environnementaux potentiels liés à la 626 production de maïs à des fins énergétiques au Québec. Environnement Canada, Saint627 Laurent Vision 2000, Montréal, pp. 78

628 Fernandes I, Penha J, Zuanon J (2015) Size-dependent response of tropical wetland fish 629 communities to changes in vegetation cover and habitat connectivity. Landscape Ecology $630 \quad 30: 1421-1434$

631 Foubert A, Le Pichon C, Mingelbier M, Farrell JM, Morin J, Lecomte F (2018) Modeling 632 the effective spawning and nursery habitats of northern pike within a large 633 spatiotemporally variable river landscape (St. Lawrence River, Canada). Limnology and 634 Oceanography 64(2):803-819 
635 Gagliardi B, Pettigrove V (2013) Removal of intensive agriculture from the landscape 636 improves aquatic ecosystem health. Agriculture, Ecosystems \& Environment 176:1-8

637 Gorski K, De Leeuw JJ, Winter HV et al (2011) Fish recruitment in a large, temperate 638 floodplain: the importance of annual flooding, temperature and habitat complexity. 639 Freshwater Biology 56(11):2210-2225

640 Goto D, Hamel MJ, Hammen JJ, Rugg ML, Pegg MA, Forbes VE (2015) Spatiotemporal 641 variation in flow-dependent recruitment of long-lived riverine fish: Model development 642 and evaluation. Ecological Modelling 296:79-92

643 Hanke MH, Lambert JD, Smith KJ (2013) Utilization of a multicriteria least cost path 644 model in an aquatic environment. International Journal of Geographical Information 645 Science 28(8):1642-1657

646 Holland LE, Huston ML (1984) Relationship of young-of-the- year northern pike to aquatic 647 vegetation types in backwaters of the upper Mississippi River. North American Journal of 648 Fisheries Management 4:514-522

649 Ishiyama N, Akasaka T, Nakamura F (2014) Mobility-dependent response of aquatic 650 animal species richness to a wetland network in an agricultural landscape. Aquatic Sciences 651 76(3):437-449

652 Jeffres C, Moyle P (2012) When Good Fish Make Bad Decisions: Coho Salmon in an 653 Ecological Trap. North American Journal of Fisheries Management 32(1):87-92

654 Johnson FH (1957) Northern pike year-class strength and spring water levels. Transactions 655 of the American Fisheries Society 86:285-293

656 Junk WJ, Bayley PB, Sparks RE (1989) The Flood Pulse Concept in River-Floodplain 657 Systems. Can. Spec. Publ. Fish. Aquat. Sci. :110-127

658 Le Pichon C, Gorges G, Faure T, Boussard H (2006) Anaqualand 2.0 : freeware of 659 distances calculations with frictions on a corridor. Cemagref, Antony. 660 https://www6.rennes.inra.fr/sad/Outils-Produits/Outils-informatiques/Anaqualand,

661 Le Pichon C, Mingelbier M, Legros M, Foubert A, Brodeur P (2018) Effets du réseau 662 routier sur la connectivité des frayères du grand brochet (Esox lucius) au lac Saint-Pierre 663 (fleuve Saint-Laurent, Canada). Le Naturaliste Canadien 142:78-91

664 Martin J, Létourneau G (2011) Changements dans les milieux humides du fleuve Saint665 Laurent de 1970 à 2002. Environnement Canada, Direction générale des sciences et de la 
666 technologie, Monitoring et surveillance de la qualité de 1' 'eau au Québec, Rapport 667 technique numéro 511, pp. 302

668 Matsuzaki S-iS, Terui A, Kodama K, Tada M, Yoshida T, Washitani I (2011) Influence of

669 connectivity, habitat quality and invasive species on egg and larval distributions and local

670 abundance of crucian carp in Japanese agricultural landscapes. Biological Conservation

671 144(8):2081-2087

672 Miehls SM, Dettmers JM (2011) Factors Influencing Habitat Shifts of Age-0 Yellow Perch

673 in Southwestern Lake Michigan. Transactions of the American Fisheries Society 674 140(5):1317-1329

675 Mingelbier M, Brodeur P, Morin J (2008) Spatially explicit model predicting the spawning 676 habitat and early stage mortality of Northern pike (Esox lucius) in a large system: the St.

677 Lawrence River between 1960 and 2000. Hydrobiologia 601(1):55-69

678 Mingelbier M, Douguet T (1999) Répertoire-synthèse des aménagements fauniques de la 679 plaine inondable du lac Saint-Pierre. Société de la faune et des parcs du Québec, Direction 680 de la faune et des habitats, pp. 37

681 Morin J, Bouchard A (2000) Les bases de la modélisation du tronçon Montréal / Trois682 Rivières. Rapport scientifique SMC-Hydrométrie RS-100. Environnement Canada, pp. 56 683 Morin J, Champoux O, Martin S, Turgeon K (2005) Modélisation intégrée de la réponse 684 de l'écosystème dans le fleuve Saint-Laurent : Rapport final des activités entreprises dans 685 le cadre du Plan d'étude sur la régularisation du lac Ontario et du fleuve Saint-Laurent. 686 Rapport scientifique - RS-108. Environnement Canada, SMC-Hydrologie, pp. 139

687 Morin J, Leclerc M, Secretan Y, Boudreau P (2000) Integrated two-dimensional 688 macrophytes-hydrodynamic modeling. Journal of Hydraulic Research 38:163-172

689 Morin J, Mingelbier M, Bechara JA et al (2003) Emergence of New Explanatory Variables 690 for 2D Habitat Modelling in Large Rivers: The St. Lawrence Experience. Canadian Water 691 Resources Journal 28

692 Mortsch L, Hengeveld H, Lister M et al (2000) Climate Change Impacts on the Hydrology 693 of the Great Lakes - St. Lawrence System. Canadian Water Ressources Journal 25(2):153$694 \quad 179$

695 Nilsson C, Reidy CA, Dynesius M, Revenga C (2005) Fragmentation and Flow Regulation 696 of the World's Large River Systems. Science 308:405-408 
697 Ospina-Alvarez A, Parada C, Palomera I (2012) Vertical migration effects on the 698 dispersion and recruitment of European anchovy larvae: From spawning to nursery areas. 699 Ecological Modelling 231:65-79

700 Peake S (2004) Effect of Approach Velocity on Impingement of Juvenile Northern Pike at

701 Water Intake Screens. North American Journal of Fisheries Management 24(2):390-396

702 Raat AJP (2001) Ecological rehabilitation of the Dutch part of the River Rhine with special

703 attention to the fish. Regulated Rivers: Research \& Management 17(2):131-144

704 Richard G, Côté D, Mingelbier M, Jobin B, Morin J, Brodeur P (2011) Utilisation du sol 705 dans la plaine inondable du lac Saint-Pierre (fleuve Saint-Laurent) durant les périodes 706 1950, 1964 et 1997: interprétation de photos aériennes, numérisation et préparation d'une 707 base de données géoréférencées. Ministère des Ressources naturelles et de la Faune, 708 Gouvernement du Québec, pp. 42

709 Roy M, Le Pichon C (2017) Modelling functional fish habitat connectivity in rivers: a case 710 study for prioritizing restoration actions targeting brown trout. Aquatic Conservation:

711 Marine and Freshwater Ecosystems 27:927-937

712 Schiemer F, Keckeis H, Kamler E (2003) The early life history stages of riverine fish:

713 ecophysiological and environmental bottlenecks. Comparative Biochemistry and

714 Physiology 133:439-449

715 Schiemer F, Keckeis H, Reckendorfer W, Winkler G (2001) The "inshore retention

716 concept" and its significance for large rivers. River Systems 12(2-4):509-516

717 Sheaves M, Baker R, Nagelkerken I, Connolly RM (2014) True Value of Estuarine and

718 Coastal Nurseries for Fish: Incorporating Complexity and Dynamics. Estuaries and Coasts

719 38(2):401-414

720 Smith BM, Farrell JM, Underwood HB, Smith SJ (2007) Year-Class Formation of Upper

721 St. Lawrence River Northern Pike. North American Journal of Fisheries Management

722 27(2):481-491

723 Timm AL, Pierce RB (2015) Vegetative substrates used by larval northern pike in Rainy

724 and Kabetogama Lakes, Minnesota. Ecology of Freshwater Fish 24(2):225-233

725 Tockner K, Stanford JA (2002) Riverine flood plains: present state and future trends.

726 Environmental Conservation 29(03) 
727 Turgeon K, Morin J (2005) Modelling submerged macrophytes distribution: evaluation of 728 models transferability in three St. Lawrence River sections. Scientific report MSC Québec 729 -Hydrology Section RS-105, Environment Canada, Sainte-Foy, pp. 61

730 Washitani I (2007) Restoration of biologically-diverse floodplain wetlands including 731 paddy fields. Global Environmental Research 11:135-140

732 Wiens JA (2002) Riverine landscapes: taking landscape ecology into the water. Freshwater 733 Biology 47:501-515

734

735 
737 Tab.1 The total surface of potential habitats for the four hydrological profiles (stable-low,

738 stable-high, increase, decrease) was calculated for potential spawning habitats at maximal

739 spawning time (developed in Mingelbier et al. 2008) and nursery habitats five weeks later

740 at the beginning of free-swimming stage (Foubert et al. 2018) in Lake Saint-Pierre (St.

741 Lawrence River, Canada)

742

743 Tab.2 Dimensionless resistance values based on the restricting/facilitating effects of

744 hydrological and land-use landscape characteristics on connectivity in downstream or

745 upstream directions. Water depth, current speed, ditch and stream networks, emerged roads

746 and dense vegetation are simulated at the beginning of free-swimming stage (Weeks).

747 Water depth corresponds to the dewatering between the spawning time $\left(\mathrm{Week}_{0}\right)$ and the

748 free-swimming stage (Week ${ }_{5}$ ) in Lake Saint-Pierre (St. Lawrence River, Canada)

750 Tab.3 Effects of landscape features that limit connectivity (i.e. water depth, current speed, 751 roads and dense vegetation) on potential spawning habitat losses for the four hydrological

752 profiles (stable-low, stable-high, increase, decrease) in Lake Saint-Pierre (St. Lawrence

753 River, Canada). The connected spawning habitat area is the result of a subtraction between

754 the potential spawning habitat area (Habitat Suitability Indices) and total habitat losses

755 Fig. 1 conceptual diagram that describes the methodological steps (in blue) leading to the

756 main results (in black) of the study 
758 Fig. 2 Map showing the largest fluvial lake in the St. Lawrence River: Lake Saint-Pierre

759 and its archipelago (Québec, Canada). Fish managed wetlands, ditch and stream networks,

760 and roads on the floodplain have been located. Flooding surfaces of three contrasting spring

761 water discharges (low, medium, high) were presented

762

763 Fig. 3 Temporal values of northern pike spawning and nursery habitats reconstructed for

764 the period 1965-2013 in the unaltered (without agriculture) and the contemporary

765 landscape (with agriculture) of Lake Saint-Pierre (St. Lawrence River, Canada). Potential

766 spawning and nursery habitat surfaces (left y-axis) in the unaltered landscape have been

767 adapted from Mingelbier et al. (2008) and Foubert et al. (2018) respectively. Remaining

768 spawning and nursery habitat surfaces include losses generated by annual agricultural

769 practices. Water discharge (right y-axis) is measured during the spawning time (Week $)$

770 and five weeks later at the beginning free-swimming stage $\left(W_{e} e_{5}\right)$. Temporal values of

771 habitats (x-axis) were classified according to water discharges (from lowest to highest).

772

773 Fig. 4 Map of Lake Saint-Pierre (St. Lawrence River, Canada) showing the potential

774 spawning and nursery habitats of the four hydrological profiles (stable-low, stable-high,

775 increase, decrease). Wetlands managed for fish (black outlines) generated potential habitats

776 when water discharge was medium to high.

777

778 Fig. 5 Map of Lake Saint-Pierre (St. Lawrence River, Canada) showing the spawning

779 habitats disconnected and connected for the four hydrological profiles (stable-low, stable-

780 high, increase, decrease) taking into account the hydrological and anthropogenic 
781 characteristics of the landscape (i.e. water depth, current speeds, ditch and stream networks,

782 roads, dense wetlands). The connectivity values correspond to three classes: (1) spawning

783 habitats overlapping nurseries (dark blue color), (2) spawning habitats connected when $\alpha$

$784 \leq 6000 \mathrm{~m}$ functional (medium blue color), and (3) spawning habitats never connected to a

785 nursery (functional distance $>6000 \mathrm{~m}$ functional; brown color). Since $\alpha$ is a distance

786 integrating the minimal cumulative resistance (i.e. functional distance), the $\alpha$ unit is not

787 equivalent to the distance in the watercourse (i.e. international metric system)

788

789 Fig. 6 The connected spawning habitats were overlaid to the contemporary land-use of

790 Lake Saint-Pierre (description 2014') to identify effective (green and blue colors) and

791 ineffective (yellow, orange and red colors) spawning habitats for the four hydrological

792 profiles (stable-low, stable-high, increase, decrease)

793

794 Fig. 7 Spawning habitat area as (1) potential, (2) connected, (3) effective and (4) recurrent

795 in the Lake Saint-Pierre floodplain (St. Lawrence River, Canada). Recurrent habitats are

796 effective spawning habitats located at the same location during the four hydrological

797 profiles (stable-low, stable-high, increase, decrease)

798 


\section{Objective 1}

Historical habitat losses due to agriculture

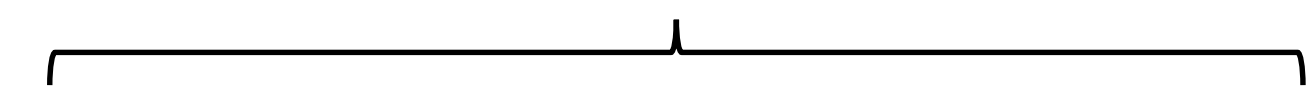

Potential

habitats

\section{Land-use}

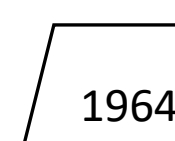
Annual crops only
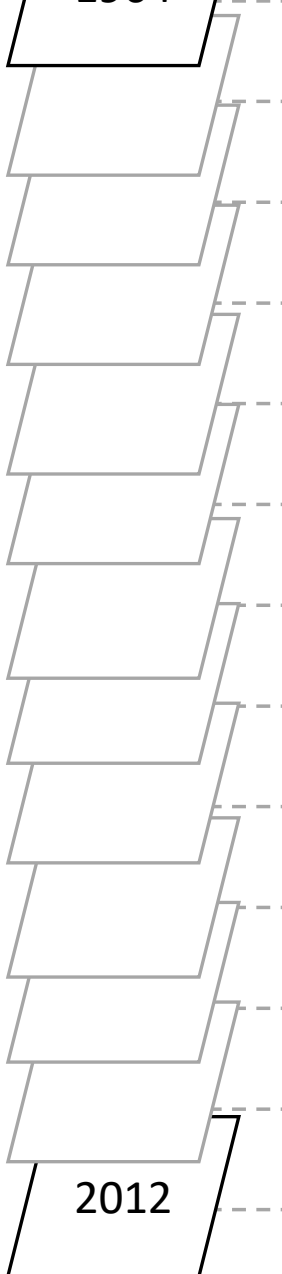

\section{Objective 2}

eto accessdoownload
Objective 3

Effective spawning analyses

Connectivity analyses between spawning habitats and nurseries

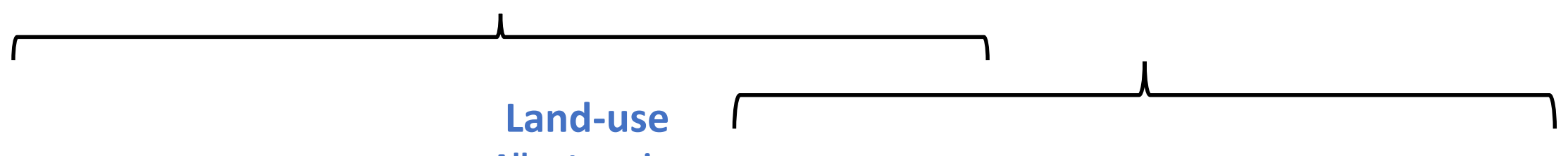

\section{Potential}

habitats
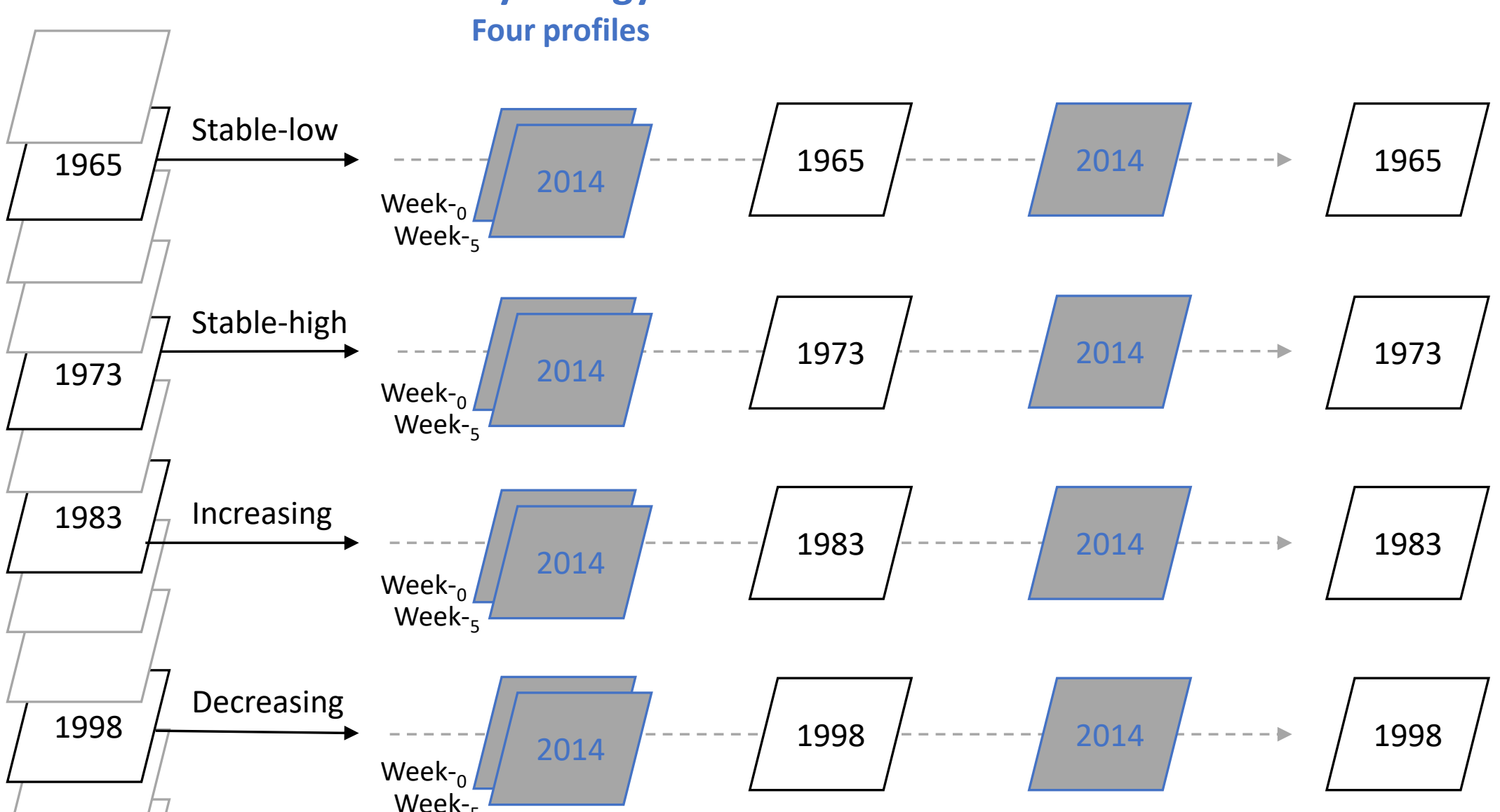

Effective habitats

\section{Hydrology}

Four profiles

\section{habitats \\ Land-use \\ All categories}
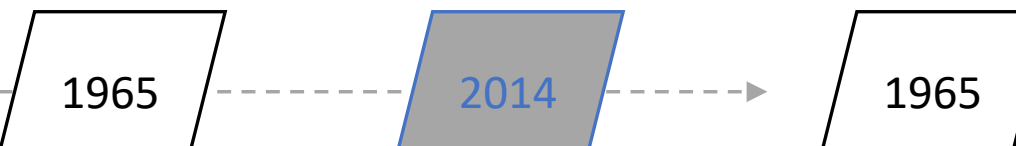

1973

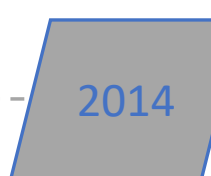

1973

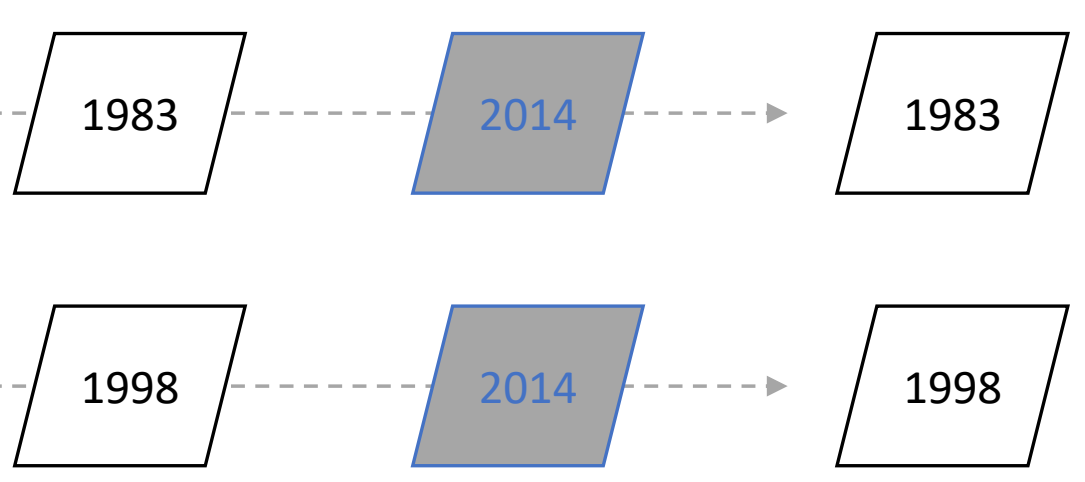

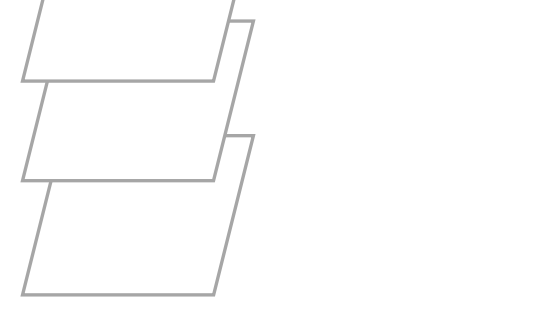



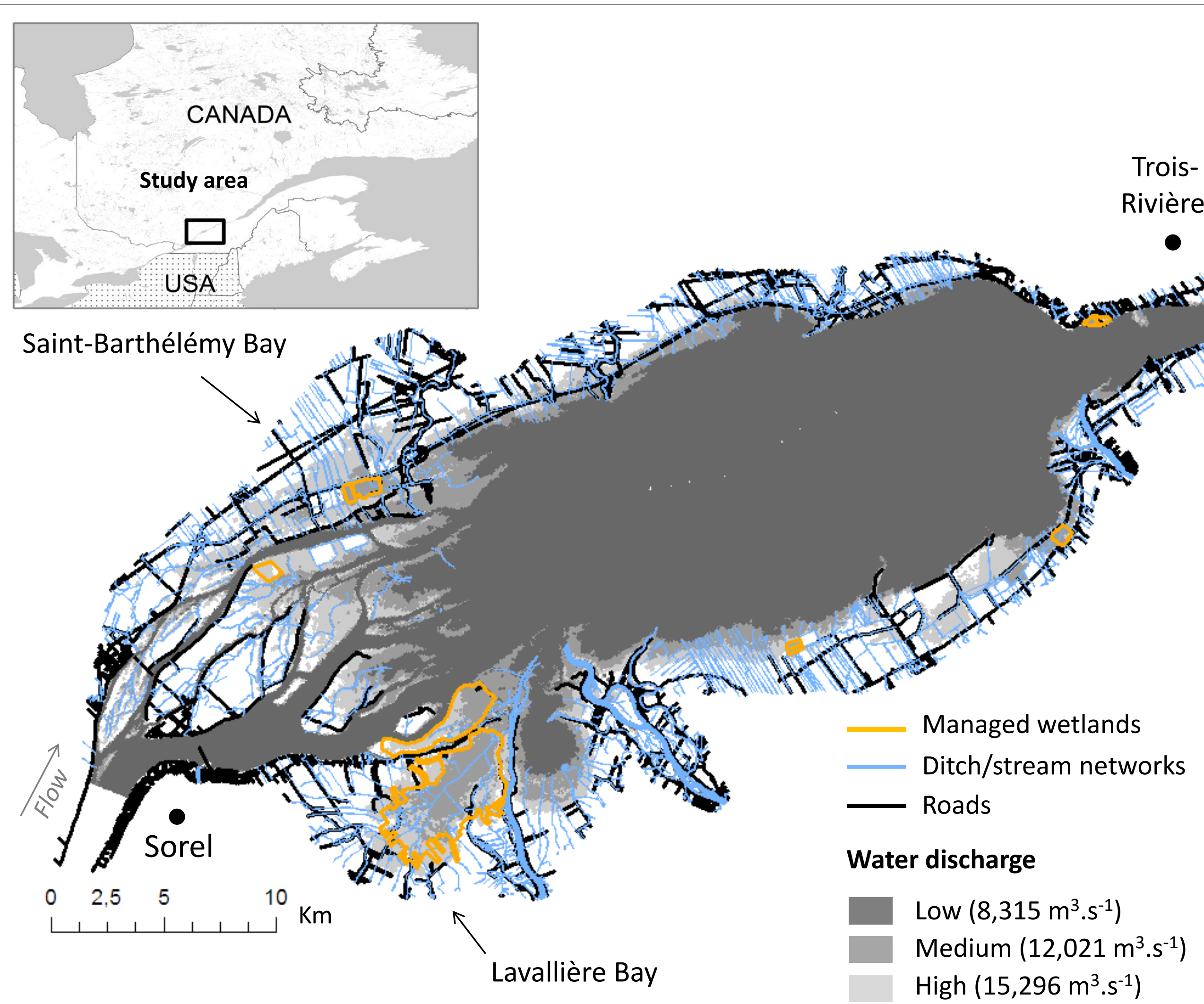


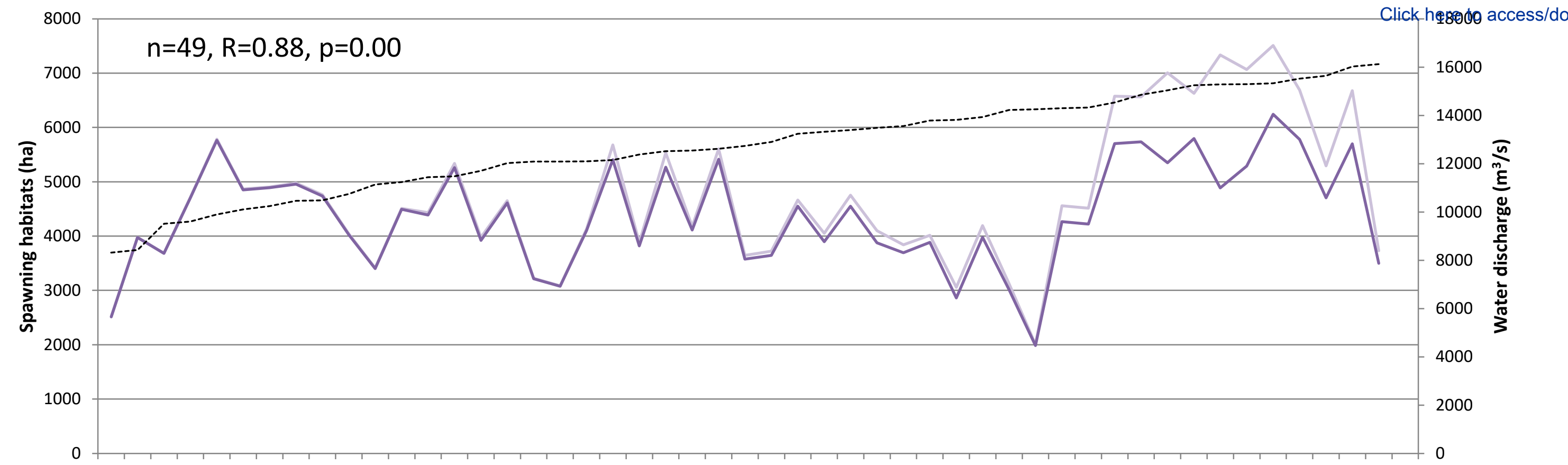

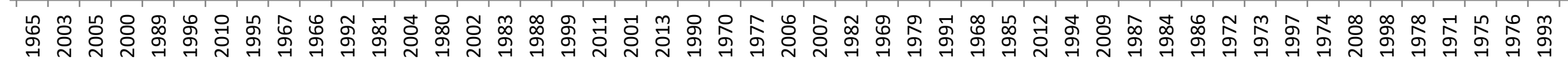

- Potential habitats — Remaining habitats -------Water discharge

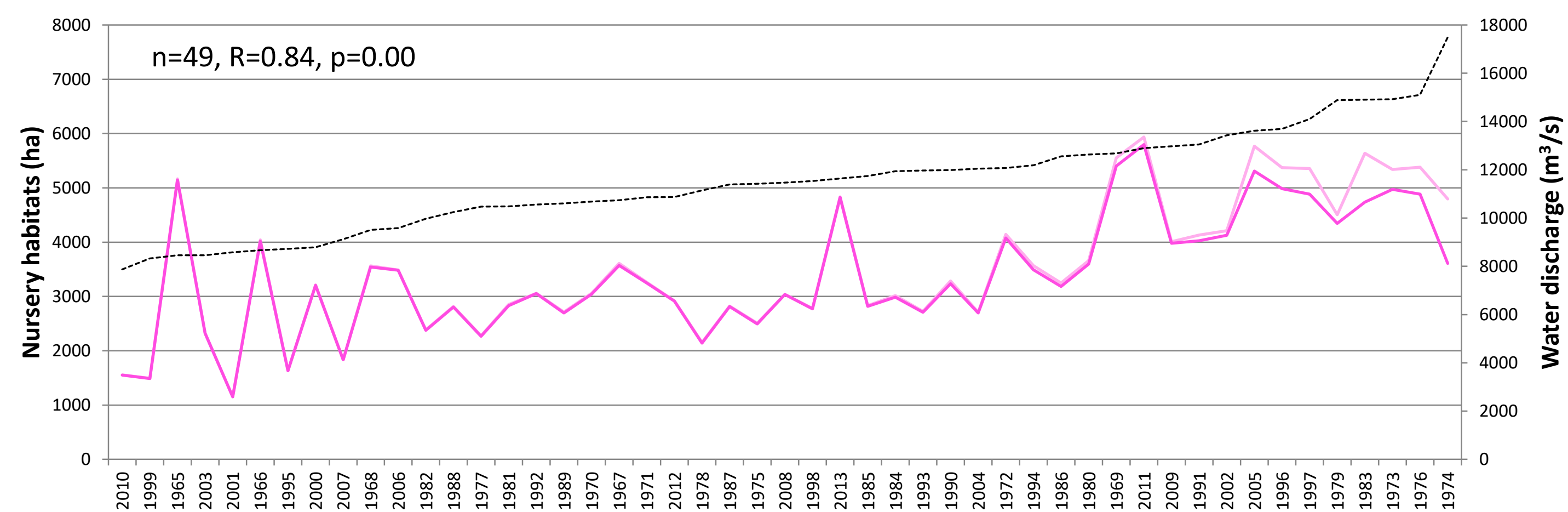

Potential habitats - Remaining habitats ------- Water discharge 
Figure 4

\section{Low discharge} (1965)

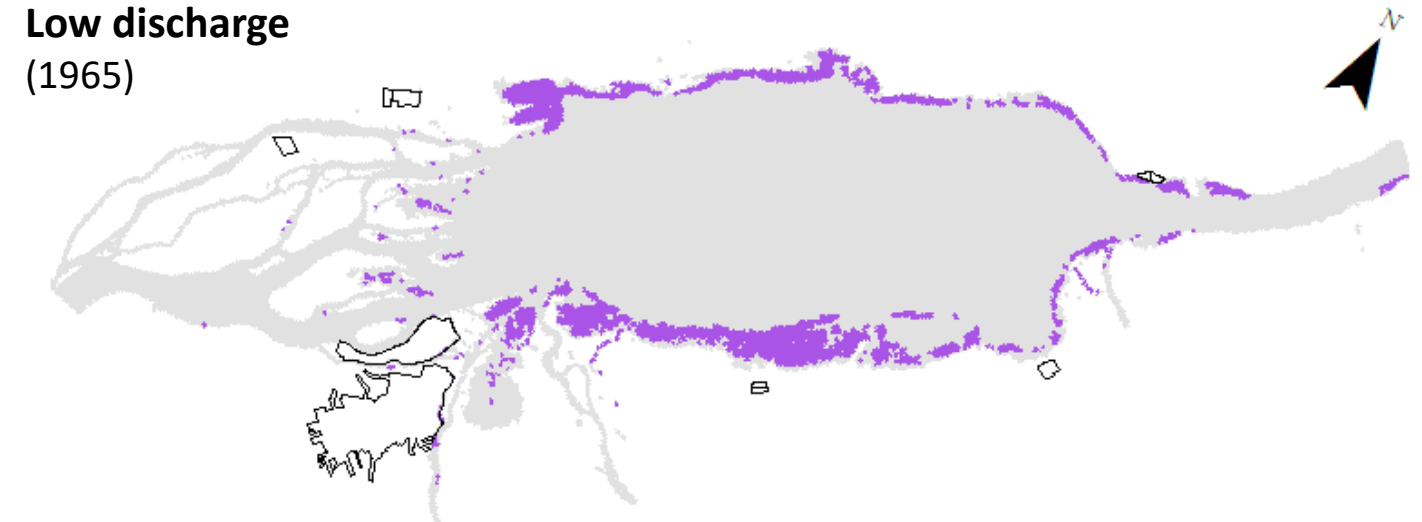

\section{High discharge}

(1973)

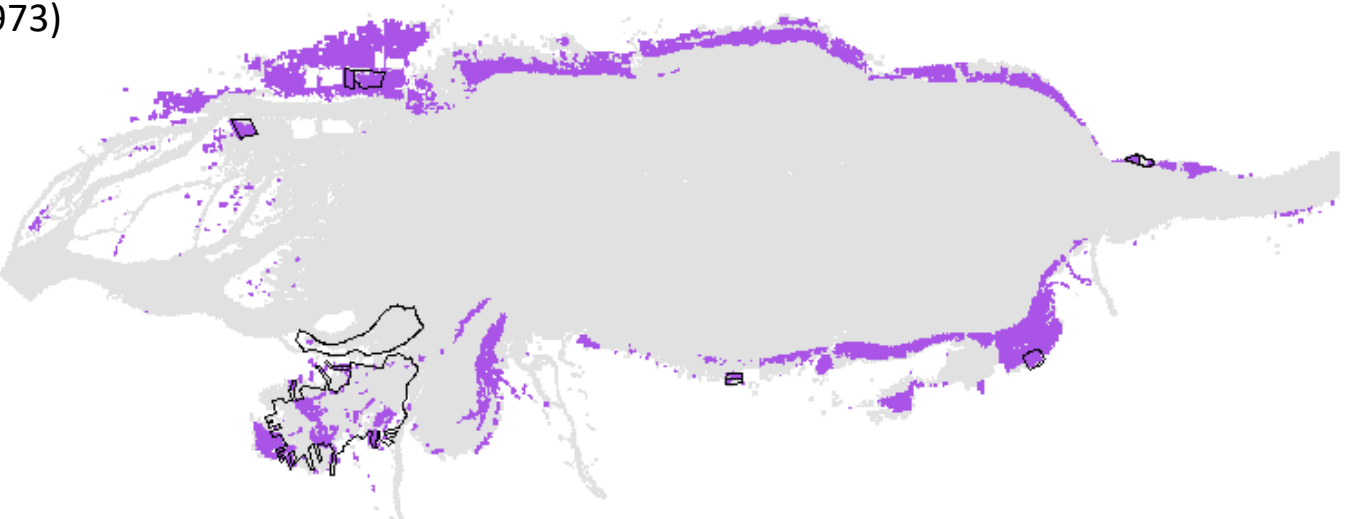

\section{Medium discharge} (1983)

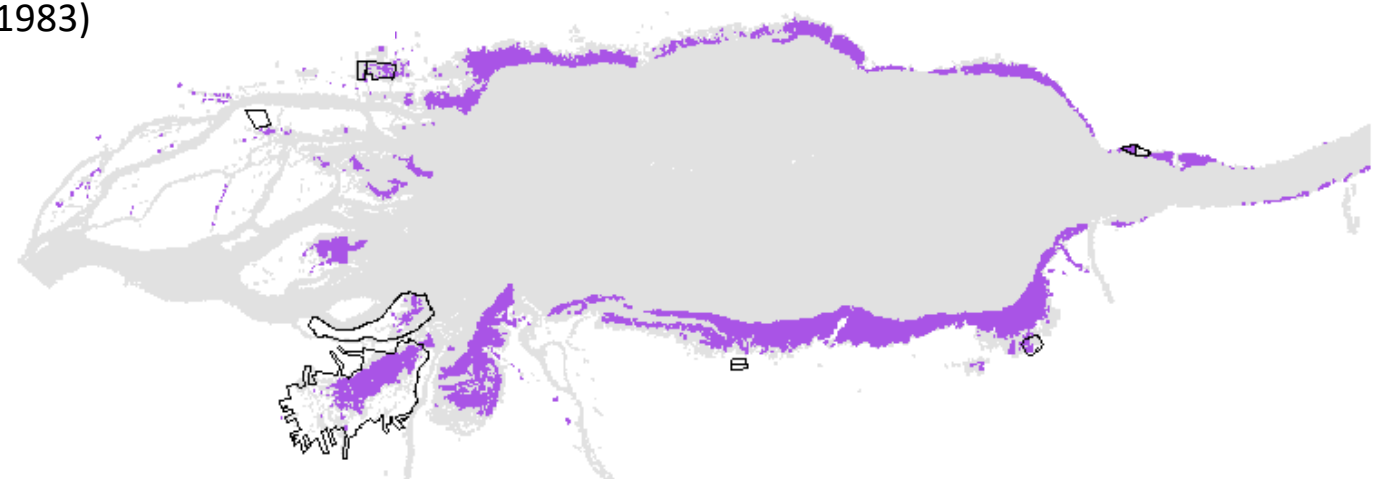

\section{High discharge}

(1998

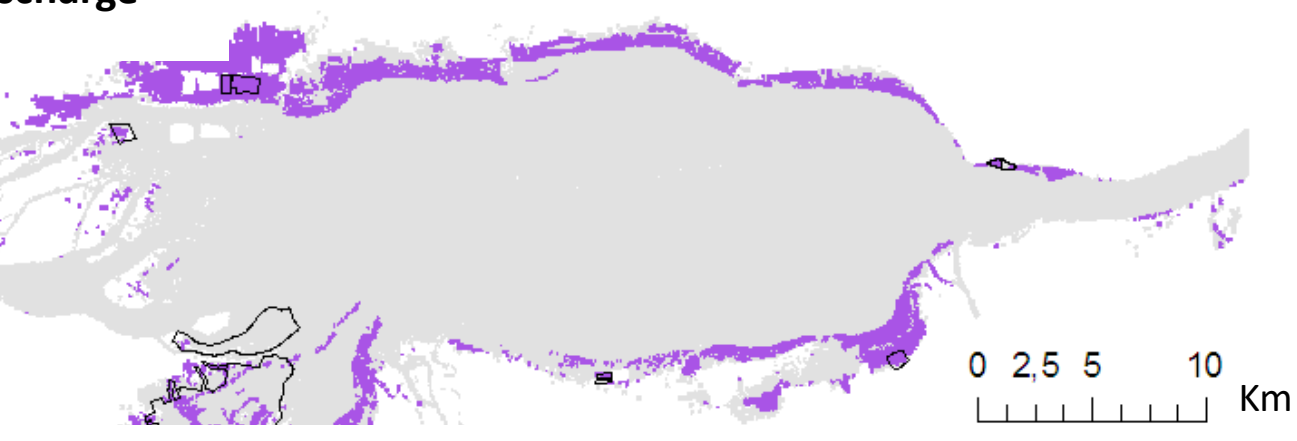

\section{Low discharge}

(1965)

Nuriserey habitats

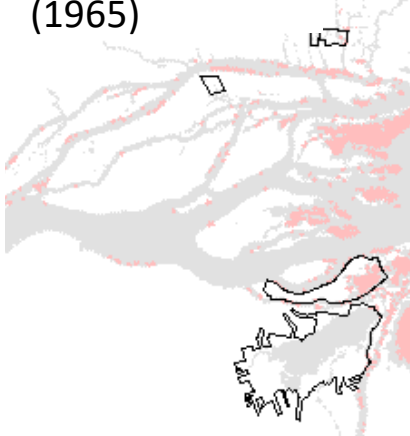

High discharge

(1973)

\section{High discharge}

(1983)

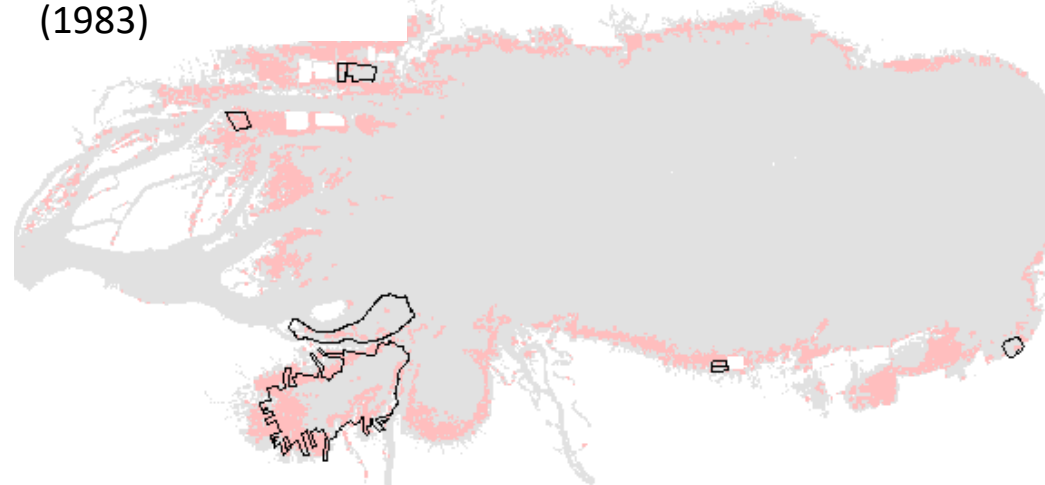

Medium discharge

(1998)

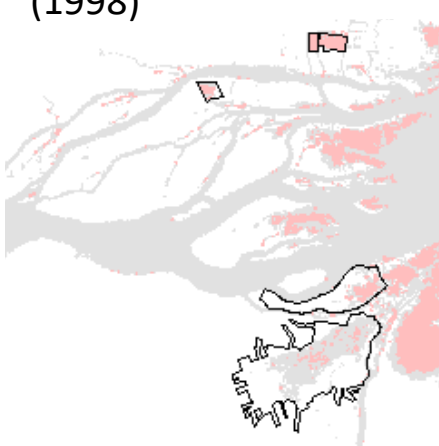



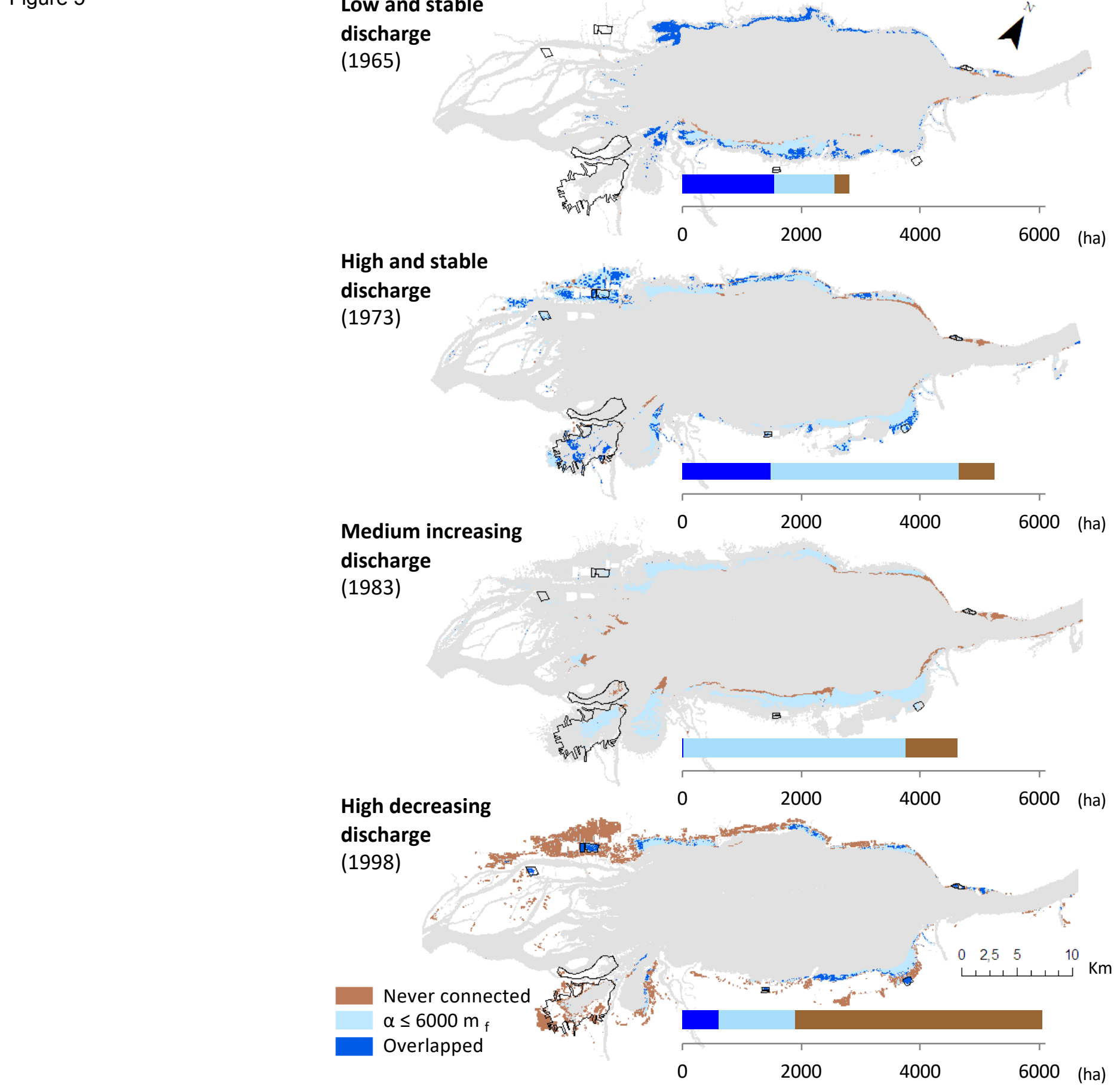


\section{Low and stable} discharge (1965)

High and stable discharge (1973)

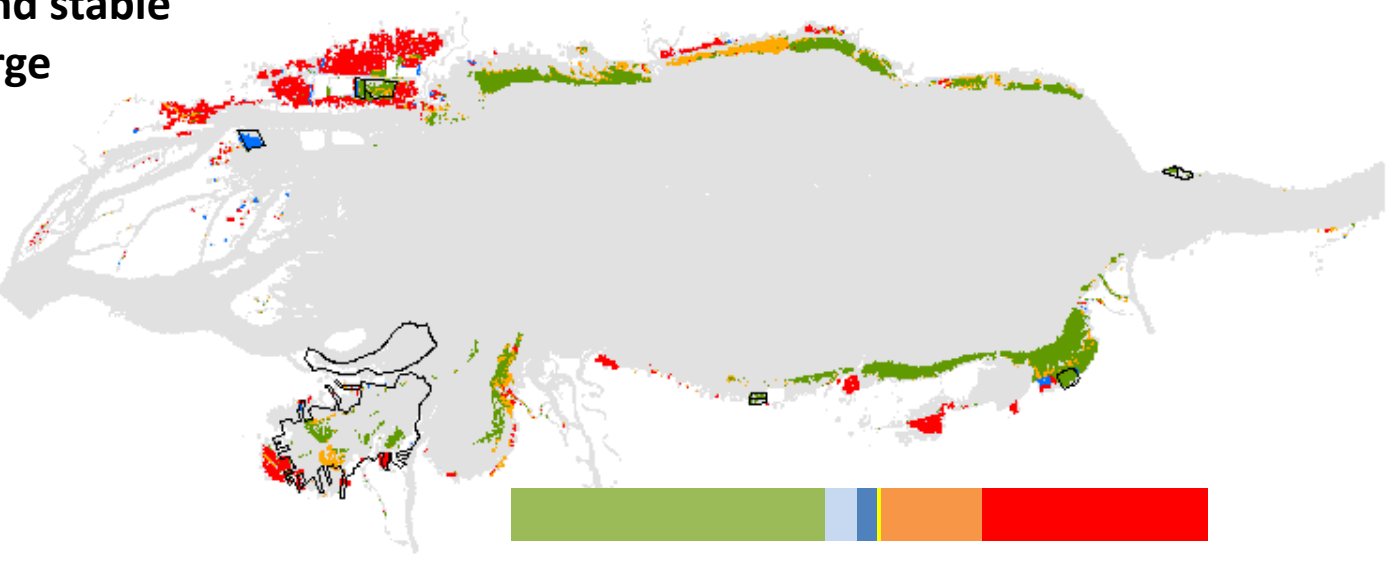

\section{Medium increasing}

\section{discharge} (1983)

\section{High decreasing} discharge (1998)

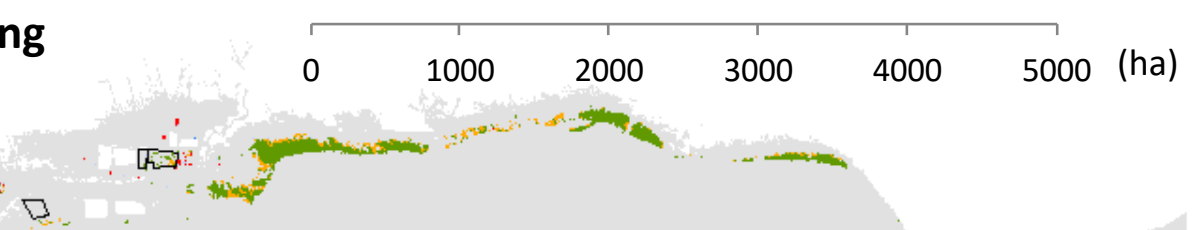

\section{Land use}

Suitable wetlands

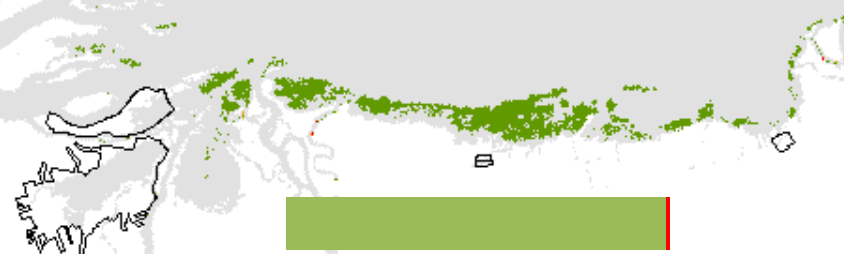

$$
\text { are }
$$

[D]

Click here to access/download;Figure;Fig.6.pdf $\underline{\underline{ }}$

Ditch/stream networks

Perennial crops

Roads and urban areas ondi:
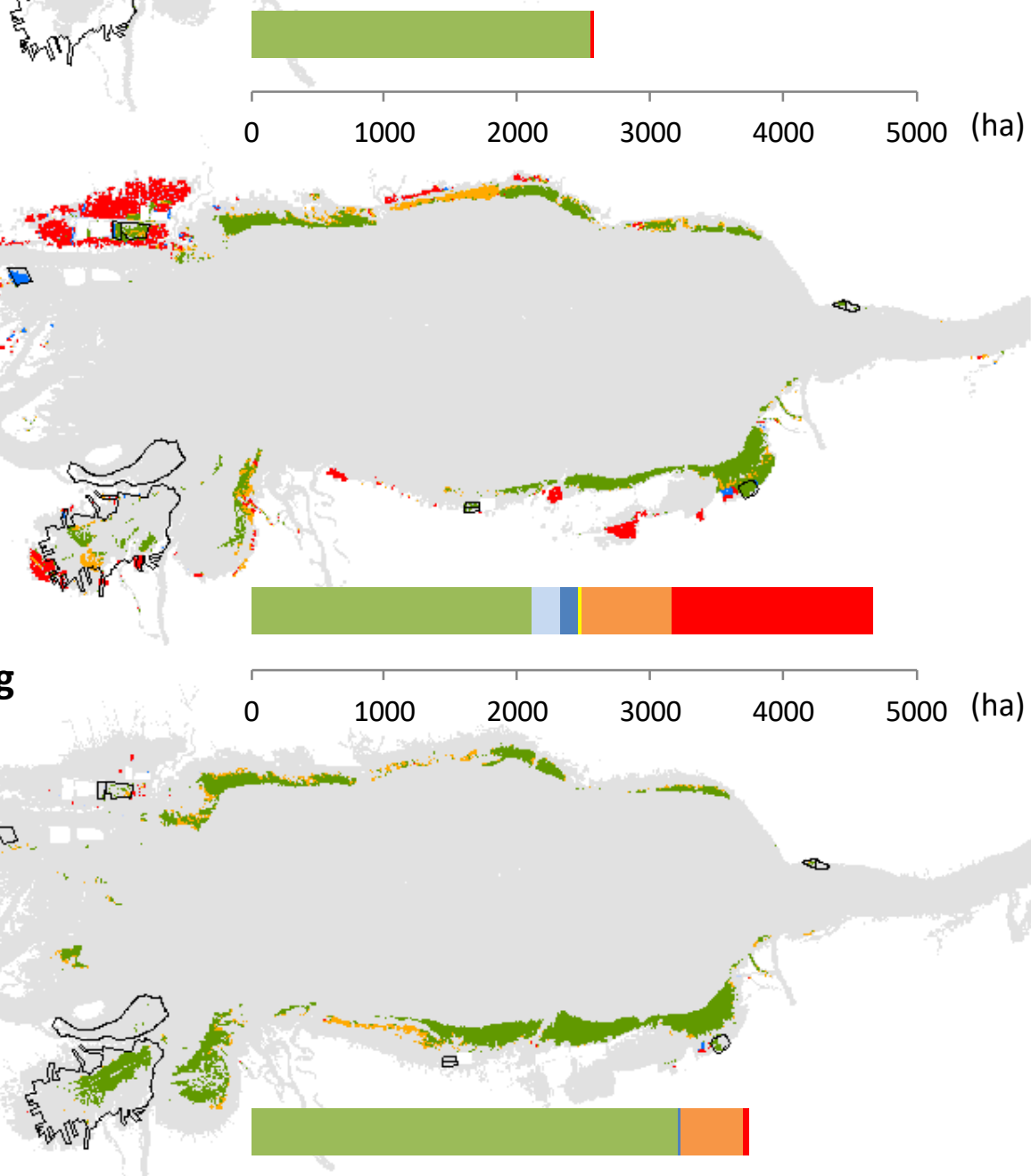

Unsuitable wetlands and wooded

Annual crops
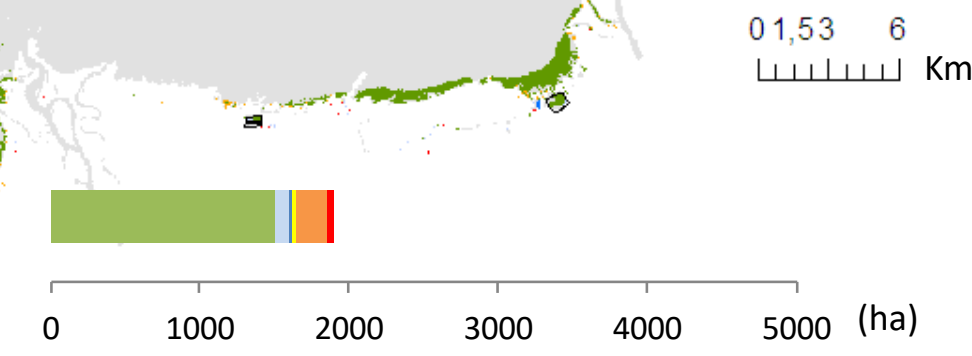
High and stable discharge

(1973)

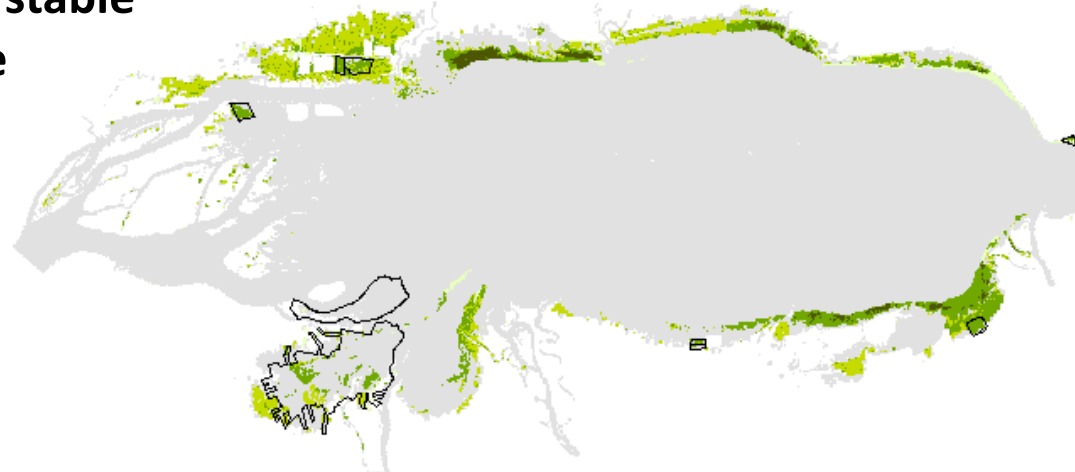

\section{Medium increasing}

discharge

(1983)
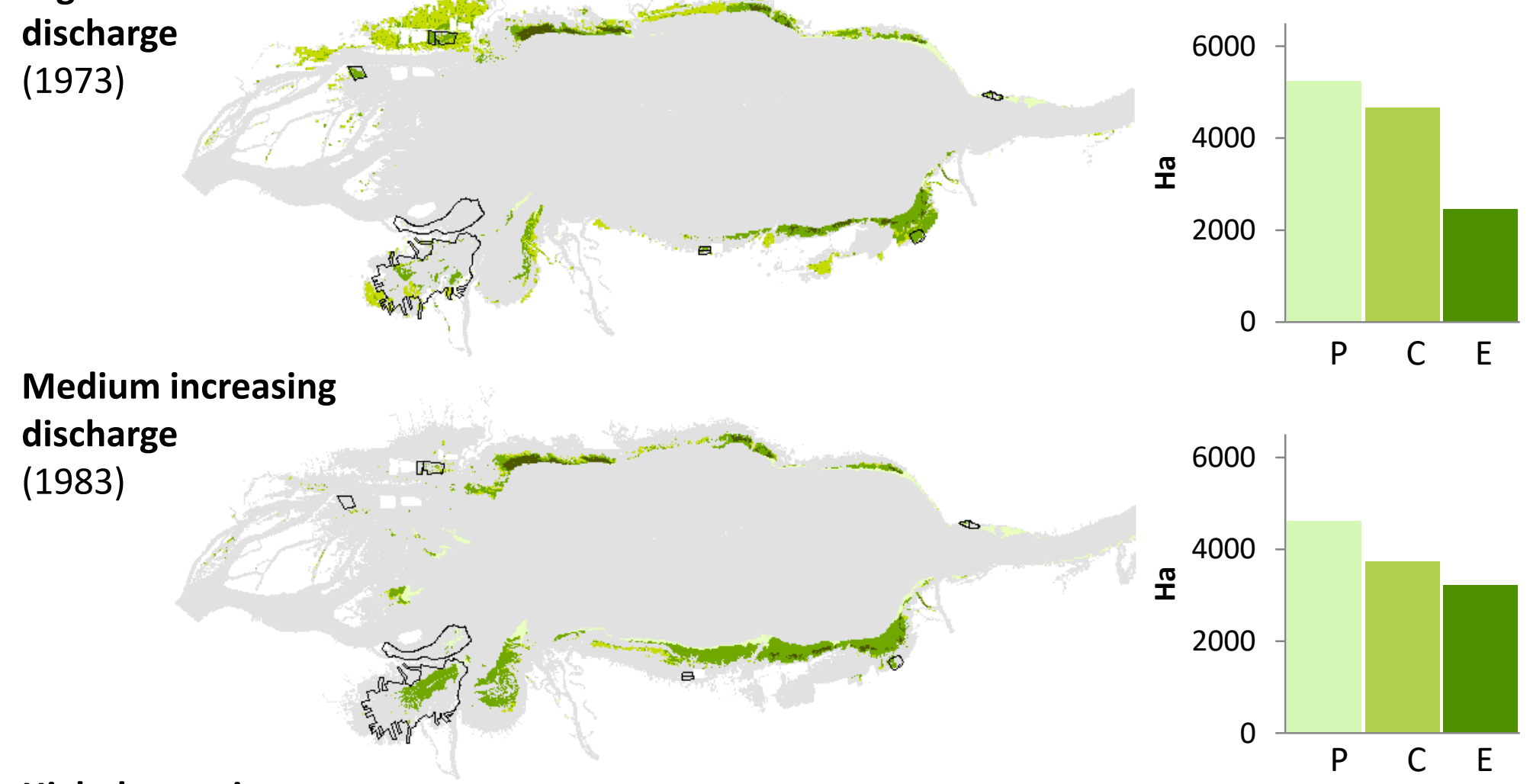

\section{High decreasing}

discharge

(1998)

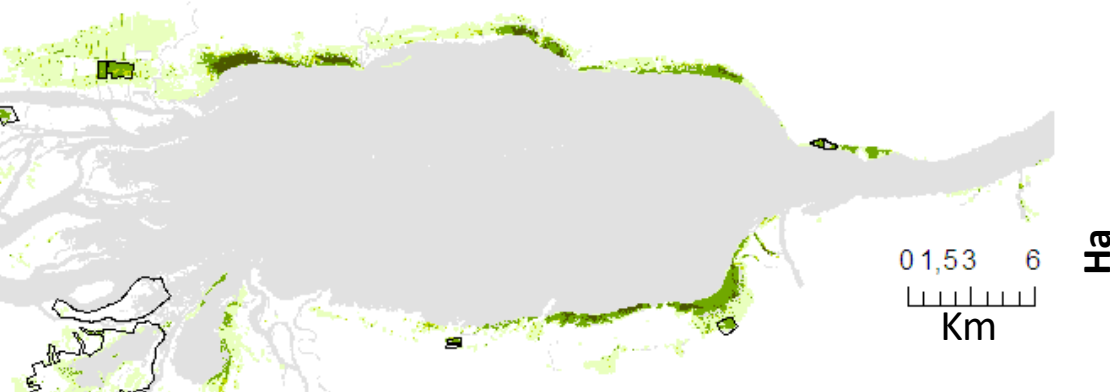

Potential (P)

Connected (C)

Effective (E)

Recurrent (332 ha)

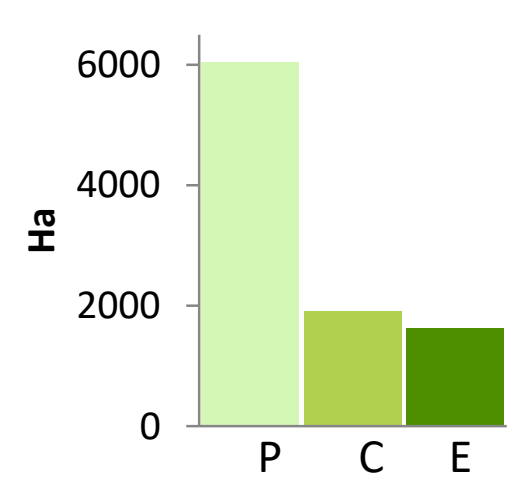




\begin{tabular}{|c|c|c|c|}
\hline Flow profiles & $\begin{array}{c}\text { Water discharge } \\
\left(\mathrm{m}^{3} \cdot \mathrm{s}^{-1}\right)\end{array}$ & $\begin{array}{l}\text { Flooded } \\
\text { surface } \\
\text { (ha) }\end{array}$ & $\begin{array}{c}\text { Potential } \\
\text { habitat } \\
\text { surface (ha) }\end{array}$ \\
\hline $\begin{array}{c}\text { Stable-low (1965) } \\
\text { Spawning habitats - Week } \\
\text { Nursery habitats - Week }\end{array}$ & $\begin{array}{l}\operatorname{Low}(8,315) \\
\operatorname{Low}(8,455)\end{array}$ & $\begin{array}{l}41,768 \\
44,731\end{array}$ & $\begin{array}{l}2,794 \\
5,107\end{array}$ \\
\hline $\begin{array}{l}\text { Stable-high (1973) } \\
\text { Spawning habitats - Week } \\
\text { Nursery habitats - Week }\end{array}$ & $\begin{array}{l}\text { High }(14,853) \\
\text { High }(14,920)\end{array}$ & $\begin{array}{l}57,800 \\
58,868\end{array}$ & $\begin{array}{l}5,242 \\
5,047\end{array}$ \\
\hline $\begin{array}{l}\text { Increasing (1983) } \\
\text { Spawning habitats - Week } \\
\text { Nursery habitats - Week } \\
\text { 5 }\end{array}$ & $\begin{array}{c}\text { Medium }(12,021) \\
\text { High }(14,905)\end{array}$ & $\begin{array}{l}49,455 \\
62,099\end{array}$ & $\begin{array}{l}4,608 \\
5,277\end{array}$ \\
\hline $\begin{array}{l}\text { Decreasing (1998) } \\
\text { Spawning habitats - Week } \\
\text { Nursery habitats - Week }\end{array}$ & $\begin{array}{c}\text { High }(15,296) \\
\text { Medium }(11,532)\end{array}$ & $\begin{array}{l}59,407 \\
46,551\end{array}$ & $\begin{array}{l}6,045 \\
3,019\end{array}$ \\
\hline
\end{tabular}




\begin{tabular}{|c|c|c|c|}
\hline \multicolumn{2}{|c|}{ Landscape feature } & $\begin{array}{c}\text { Downstream } \\
\text { resistance }\end{array}$ & $\begin{array}{l}\text { Upstream } \\
\text { resistance }\end{array}$ \\
\hline \multicolumn{2}{|c|}{ Water depth $\leq 0 \mathrm{~m}$} & 10,000 & 10,000 \\
\hline \multirow{6}{*}{$\begin{array}{l}\text { Current speeds } \\
\left(\mathrm{cm}^{3} \cdot \mathrm{s}^{-1}\right)\end{array}$} & Speed $>0 \leq 2$ & 1 & 1 \\
\hline & Speed $>2 \leq 4$ & 0.3333 & 10,000 \\
\hline & Speed $>4 \leq 6$ & 0.2000 & 10,000 \\
\hline & Speed $>6 \leq 8$ & 0.1429 & 10,000 \\
\hline & Speed $>8 \leq 10$ & 0.1111 & 10,000 \\
\hline & Speed $>10$ & 10,000 & 10,000 \\
\hline \multicolumn{2}{|c|}{ Ditch and stream networks } & 1 & 1 \\
\hline \multicolumn{2}{|c|}{ Emerged roads and dikes } & 10,000 & 10,000 \\
\hline \multicolumn{2}{|c|}{ Dense vegetation } & 10,000 & 10,000 \\
\hline
\end{tabular}




\begin{tabular}{|c|c|c|c|c|c|c|c|c|c|c|c|}
\hline \multirow{2}{*}{$\begin{array}{l}\text { Flow } \\
\text { profile }\end{array}$} & \multirow{2}{*}{$\begin{array}{c}\text { Potential } \\
\text { spawning } \\
\text { habitats (ha) }\end{array}$} & \multicolumn{5}{|c|}{ Direct losses (i.e. transform high to low habitat quality) } & \multicolumn{4}{|c|}{ Indirect losses (i.e. act as physical barriers) } & \multirow{2}{*}{$\begin{array}{c}\text { Connected } \\
\text { spawning } \\
\text { habitats (ha) }\end{array}$} \\
\hline & & $\begin{array}{c}\text { Dewatered } \\
\text { areas }\end{array}$ & $\begin{array}{l}\text { High speeds } \\
\left(>10 \mathrm{~cm} \cdot \mathrm{s}^{-1}\right)\end{array}$ & Roads & $\begin{array}{c}\text { Dense } \\
\text { wetlands }\end{array}$ & $\begin{array}{c}\text { Total } \\
\text { (ha) [\%] }\end{array}$ & $\begin{array}{l}\text { High speeds } \\
\left(>10 \mathrm{~cm} \cdot \mathrm{s}^{-1}\right)\end{array}$ & Roads & $\begin{array}{c}\text { Dense } \\
\text { wetlands }\end{array}$ & $\begin{array}{c}\text { Total } \\
\text { (ha) [\%] }\end{array}$ & \\
\hline Stable-low & 2,794 & 4 & 223 & 2 & 0 & $229[8 \%]$ & 5 & 0 & 0 & $5 \quad[0.2 \%]$ & 2,560 \\
\hline Stable-high & 5,242 & 51 & 262 & 100 & 26 & $439[8 \%]$ & 110 & 28 & 0 & $138[3 \%]$ & 4,665 \\
\hline Increase & 4,608 & 2 & 772 & 8 & 0 & $782[17 \%]$ & 82 & 0 & 0 & $82[2 \%]$ & 3,744 \\
\hline Decrease & 6,005 & 3,758 & 61 & 117 & 66 & $4,002[66 \%]$ & 72 & 0 & 25 & $97 \quad[2 \%]$ & 1,906 \\
\hline
\end{tabular}


Céline Le Pichon

Hydro-ecology, IRSTEA

To:

\section{Landscape Ecology}

1 rue Pierre-Gilles de Gennes

CS 10030, F92761 Antony Cedex, France

Tel: +33140966177

Fax: +33140966199

E-mail : celine.lepichon@irstea.fr

\section{Dear Editors,}

Please find enclosed a paper by Aline Foubert, Frédéric Lecomte, Philippe Brodeur, Céline Le Pichon and Marc Mingelbier entitled "Losing the best conditions for effective fish spawning habitat in the floodplain due to riparian agriculture and flow regulation, St. Lawrence River, Canada". This paper presents original findings not published nor being submitted for publication elsewhere. All coauthors have contributed significantly to the present work and agreed for submitting the manuscript to Landscape Ecology. The manuscript was proofread by a colleague who is a native English speaker. We accept to pay for the extra costs for producing the colour figures included in the manuscript.

"Riverscape" ecology, a new emerging concept applying landscape ecology fundamentals to the aquatic realm, proposes to consider the riverine ecosystems as a continuum where spatio-temporal dynamics had to be quantified along its course, including areas impacted by humans. Holistic, spatially explicit approaches are now considered as a prerequisite for defining guiding principles for inland fisheries and watershed management.

The present manuscript quantifies how anthropogenic alterations, such as riparian agriculture and water flow regulation, have impacted the effectiveness of spawning habitats of northern pike (Esox lucius) in a large floodplain: the fluvial Lake Saint-Pierre (St. Lawrence River, Canada). Combining GIS-Based habitat modelling covering a 49-years period (1965-2013) to historical land-use analyses and least-cost modelling of the aquatic connectivity allowed the present study to identify a paradigm shift in the relationship between flow conditions and pike recruitment. The highest potential for reproduction, usually associated with high and stable water flows, has been lost due to (1) the intensive agriculture in the upper floodplain that overlaps with suitable spawning habitats and nursery grounds for fish, and (2) the flow regulation that generates more frequent extreme events leading to the complete drying of spawning grounds. Our results convey important implications for fisheries management and conservation; maps identifying the most rewarding areas for restoration are now available for managers. Such information is mandatory for initiating incentive aimed at farmers to convert their use of the floodplain: from cultivating annual crops toward planting perennial crops. Moreover, the present findings stresses the need to update the Lake Ontario - St. Lawrence River flow regulation used by the International Joint Commission (IJC), a commission established between the United States and Canada to regulate water levels of shared water bodies. 


\section{$\underline{\text { Potential appropriate reviewers }}$}

Anne Timm, altimm@fs.fed.us, land use and aquatic habitat connectivity

John Farrell, jmfarrell@esf.edu ,pike

Françoise Burel francoise.burel@univ-rennes1.fr, landscape spatial dynamics and permeability to movement Isabelle Durance, durance@ cardiff.ac.uk, role of landscape processes in driving freshwater ecosystems

Current members of the Editorial Board to potentially handle the manuscript.

M. Bélisle, University of Sherbrooke, Sherbrooke, Canada (connectivity)

G. Cumming, James Cook University, Townsville, Australia (aquatic habitat:coral reef)

S.S. Luque, National Research Institute of Science and Technology for Environment and Agriculture (IRSTEA), St-Martin d'Hères Cedex, France (GIS-based spatial analysis) 
Click here to access/download ESM_1.docx

\section{Supplementary material}


Click here to access/download ESM_2.docx

\section{Supplementary material}

